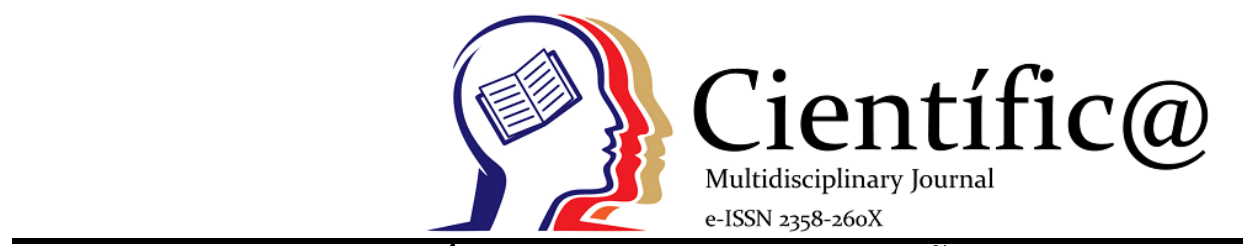

\title{
ESTUDO BIOQUÍMICO DA FERMENTAÇÃO DO CUPUAÇU (THEOBROMA GRANDIFLORUM SCHUM)
}

\author{
BIOCHEMICAL STUDY OF CUPUAÇU FERMENTATION (THEOBROMA GRANDIFLORUM \\ SCHUM
}

\author{
Adilson Ferreira Santos Filho*1, Maricely Jannette Uría Toro²
}

\begin{abstract}
${ }^{* 1}$ Autor para correspondência; Tecnólogo em alimentos - Universidade Estadual do Pará, Belém - PA, Brasil. e-mail: adilsonferreirasf@gmail.com

${ }^{2}$ Doutora em Química do Curso de Tecnologia de Alimentos da Universidade Estadual do Pará, Belém - PA, Brasil. e-mail: maryuria12@hotmail.com
\end{abstract}

\section{Info}

Recebido: 06/2020

Publicado: $12 / 2020$

DOI: $10.29247 / 2358-260 X .2020 v 7 i 2.4561$

ISSN: 2358-260X

Palavras-Chave
Compostos bioativos, capacidade
antioxidante, enzimas
Keywords:
Bioactive compounds, antioxidant capacity,
enzymes

\begin{abstract}
This work aimed to evaluate the various biochemical transformations that take place in the cupuaçu seed until it reaches the almond shape, analyzing the fermentation, drying and roasting process, where the behavior of $\mathrm{pH}$, temperature, soluble solids, bioactive compounds (vitamin $\mathrm{C}$, phenolics and flavonoids), antioxidant activity (by the methods of DPPH and ABTs), alkaloids (caffeine and theobromine), hydroxymethylfurfural formation and enzymatic activity (peroxidase and polyphenoloxidase) was verified. During the 168-hour fermentation period, there was a variation in acidity, temperature, a decrease in the amount of ${ }^{\circ} \mathrm{Brix}$ and an increase in $\mathrm{pH}$. A reduction in the amount of bioactive compounds was detected, including: total phenolic compounds from 381.23 to 127.24
\end{abstract}

$\mathrm{mg} / 100 \mathrm{~g}$, flavonoids from 92 to $38.25 \mathrm{mg} / 100 \mathrm{~g}$ and vitamin C content from 0.6 to $0.125 \mathrm{mg} / 100 \mathrm{~g}$. Regarding the antioxidant capacity, a decrease was observed during the processing of the seeds until obtaining the roasted almonds, with a reduction of $32.73 \%$ in the antioxidant activity by the ABTS method, while in the case of DPPH the reduction was $72 \%$. Alkaloids content in almonds was quantified after drying (theobromine $10.22 \mathrm{mg} / \mathrm{g}$ and $3.03 \mathrm{mg} / \mathrm{g}$ caffeine) and there was a small reduction when compared to roasted almonds (theobromine $9.14 \mathrm{mg} / \mathrm{g}$ and caffeine $2.6 \mathrm{mg} / \mathrm{g}$ ). The hydroxymethylfurfural content formed from the beginning $(6.94 \mathrm{mg} / \mathrm{kg}$ ) until the roasted almond $(33.87 \mathrm{mg} / \mathrm{kg}$ ) was evaluated. The behavior of the enzymatic activity of polyphenoloxidase (PPO) and peroxidase (POD) was verified during the processing of cupuaçu, observing an increase in the activity of the enzymes and a decrease in their activities after roasting, with a reduction of $96 \%$ and $98 \%$ for PPO and POD, respectively. The behavior of the Michael-Mentes constant $(\mathrm{Km})$ and the maximum speed of the enzymatic reaction during seed processing was evaluated, finding an increasing affinity between enzymes and phenolic substrates until reaching the last day of fermentation, which due to the conditions of the medium affected the affinity of the enzymes with the substrates. The physical-chemical, macro and micronutrient characterization was performed on roasted almonds, which showed nutritional potential.

\section{Resumo}

Este trabalho teve como objetivo avaliar as diversas transformações bioquímicas que ocorrem na semente de cupuaçu até atingir a forma de amêndoa, analisando-se o processo fermentativo, secagem e torrefação, onde verificou-se o comportamento do $\mathrm{pH}$, temperatura, sólidos solúveis, compostos bioativos (vitamina C , fenólicos e flavonoides), atividade antioxidante (pelos métodos de DPPH e ABTs), alcaloides (cafeína e teobromina), formação de hidroximetilfurfural e atividade enzimática (peroxidase e polifenoloxidase). Durante o período de fermentação de 168 horas, houve uma variação na acidez, temperatura, uma diminuição na quantidade de ${ }^{\circ}$ Brix e um aumento no pH. Foi detectada uma redução na quantidade de compostos bioativos, entre eles: compostos fenólicos totais de 381,23 a 127,24 


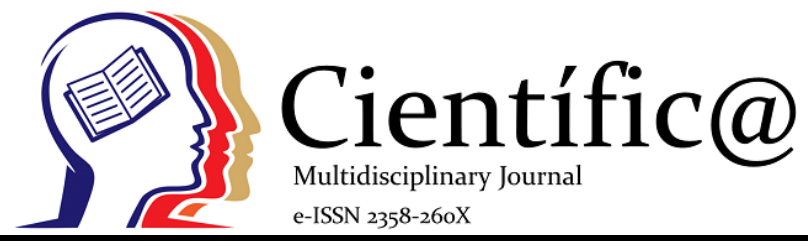

$\mathrm{mg} / 100 \mathrm{~g}$, flavonoides de 92 a 38,25 mg/100g e o teor de vitamina C de 0,6 a 0,125 mg/100g. Em relação à capacidade antioxidante, observou-se uma diminuição durante o processamento das sementes até a obtenção das amêndoas torradas, com uma redução de 32,73\% na atividade antioxidante pelo método ABTS, enquanto no caso do DPPH a redução foi de $72 \%$. 0 teor de alcaloides nas amêndoas foi quantificado após a secagem (teobromina $10,22 \mathrm{mg} / \mathrm{g}$ e cafeína $3,03 \mathrm{mg} / \mathrm{g}$ ) e houve uma pequena redução quando comparada às amêndoas torradas (teobromina 9,14 mg/g e cafeína 2,6 mg/g). 0 teor de hidroximetilfurfural formado desde o início $(6,94 \mathrm{mg} / \mathrm{kg})$ até a amêndoa torrada $(33,87 \mathrm{mg} / \mathrm{kg})$ foi avaliado. 0 comportamento da atividade enzimática da polifenoloxidase (PPO) e peroxidase (POD) foi verificado durante o processamento do cupuaçu, observando um aumento na atividade das enzimas e uma diminuição na atividades das mesmas após a torrefação, com uma redução de $96 \%$ e 98\% para PPO e POD, respectivamente. O comportamento da constante de Michael-Mentes (Km) e a velocidade máxima da reação enzimática durante o processamento das sementes foi avaliado, encontrando uma crescente afinidade entre as enzimas e os substratos fenólicos até atingir o último dia de fermentação, que devido as condições do meio afetou a afinidade das enzimas com os substratos. A caracterização físico-química, macro e micronutriente foi realizada em amêndoas torradas, como resultado apresentaram um potencial nutricional.

\section{INTRODUÇÃO}

O cupuaçu (Theobroma grandiflorum Schum.) é uma das diversas frutas nativas da Amazônia brasileira, sendo uma matéria-prima que apresenta uma grande aceitabilidade entre os consumidores, em virtude do sabor e do aroma, podendo proporcionar diversos subprodutos que apresentam grande demanda crescente de consumo, como sorvetes, sucos, geleias dentre outros (PEREIRA et al., 2017; PEREIRA et al., 2018; COSTA et al., 2019)

Segundo pesquisas de Souza (2007), em média 37\% do peso do fruto corresponde a polpa, 15\% a 20\% são sementes, 3\% é placenta e $45 \%$ é casca. O percentual de 15 a 20\% de semente, normalmente, são descartados pelo agroindústria como resíduo de produção, no entanto, esse material aparentemente sem utilidade apresenta estudos que demonstram que se pode obter das sementes do cupuaçu um chocolate semelhante ao do cacau, sendo necessário passar por processos de transformações bioquímicas para desenvolver as características peculiares do chocolate (LOPES et al., 2008; COSTA et al., 2017)
No entanto, para que se chegue até o chocolate, as sementes necessitam passar por diversas transformações, processos que ocorrem durante a fermentação, secagem e torração (Braga et al., 2018).

Durante a fermentação, ocorrem alterações físicas, químicas e bioquímicas na semente, levando à formação dos chamados "precursores de aroma e sabor". Sendo a fermentação um processo microbiológico espontâneo causado por leveduras, bactérias do ácido acético e do ácido lático que atuam em um período de 6 a 7 dias (JINAP et al., 2010; AFOAKWA et al., 2013; JANEK et al., 2016). Apresenta dois estágios bem definidos, sendo a primeira fase anaeróbica, onde se inicia muito rapidamente e tem o crescimento das leveduras favorecido devido ao teor de açúcar da polpa contida na semente, $\mathrm{pH}$ ácido e condição predominantemente anaeróbica, sendo o meio inicial propicio para o desenvolvimento dessas leveduras, as quais rapidamente consomem o oxigênio e açúcares presente na massa, fermentando e liberam etanol como produto do meio reacional (FERRÃO, 2007; AFOAKWA et al., 2013; AFOAKWA et al., 2015; TOKER et. al., 2020). 
$\mathrm{Na}$ segunda fase da fermentação, denominada de aeróbica, ocorre uma condensação oxidativa de diversos compostos. Dentre essas transformações pode se citar a oxidação dos polifenóis, os quais podem produzir ou não complexos com as proteínas e peptídeos, levando a redução da adstringência, amargor e também a mudança na coloração da semente para cor marrom. A oxidação observada nesta fase continua na etapa de secagem até que a umidade atinja um ponto mínimo no qual reduza ou acabe a atividade das enzimas, em especial a atividade da enzima polifenoloxidase e peroxidase (EFRAIM, 2004; JANEK, et al., 2016).

$\mathrm{Na}$ etapa de secagem o processo têm início logo após a fermentação, podendo ser realizado no sol ou por aquecimento, sendo que o método utilizado irá depender das condições do clima e disponibilidade de recursos do produtor. Um dos objetivos da secagem é a redução do teor de umidade das amêndoas e a volatilização dos ácidos, resultando na elevação do pH, porém, cuidados são requeridos no sentido de se evitar contaminação por microrganismos que podem se desenvolver nesse ambiente, como os gentes de putrefação e fungos tóxicos, que irão alterar o sabor da amêndoa (EFRAIM et al., 2009; GUEHI et al., 2010; PARAMO et al., 2010).

O processo de torração provoca a oxidação dos compostos, pois se aplica altas temperaturas na presença do oxigênio, sendo o responsável pelo escurecimento acentuado das amêndoas, gerando o escurecimento não enzimático, reação de Maillard, e proporcionando as características aromáticas e sensoriais do produto (WOLLGAST e ANKLAM, 2000; JINAP et al., 2010; ZAMBRANO et al., 2010; TOKER et. al., 2020).

Existem poucas pesquisas que aprofundem o conhecimento das transformações bioquímicas da semente em amêndoa de cupuaçu (Theobroma grandiflorum), sendo muitas das pesquisas voltadas para o beneficiamento do cacau, no entanto, o cupuaçu amazônico apresenta grande potencial a ser explorado, em virtude de apresentar pesquisas que indiquem a boa disponibilidade de nutrientes presente no cupuaçu (CANUTO et. al, 2010; PUGLIESE et. al, 2013).

Diante dessa situação, este trabalho teve como objetivo avaliar as diversas transformações bioquímicas que ocorrem na semente de cupuaçu até alcançar a forma de amêndoa, sendo analisado o processo fermentativo, secagem e torração, onde se acompanhou o $\mathrm{pH}$, temperatura, sólidos solúveis, o comportamento dos bioativos (vitamina $\mathrm{C}$, fenólicos e flavonoides), atividade antioxidante (pelos métodos de DPPH e ABTs), alcaloides (cafeína e teobromina), formação do hidroximetilfurfural e atividade enzimática (peroxidase e polifenoloxidase).

\section{MATERIAIS E MÉTODOS}

As sementes de cupuaçu foram obtidas de uma fábrica de processamento de frutas na comunidade da vila fortaleza no município do Acará, na região nordeste do estado do Pará.

A fermentação das sementes de cupuaçu foi realizada com $50 \mathrm{~kg}$ de sementes em uma caixa de madeira com medidas de $35 \mathrm{~cm}$ de altura, $25 \mathrm{~cm}$ de largura e $25 \mathrm{~cm}$ de comprimento. Foram feitos orifícios no fundo da caixa para facilitar o escoamento dos líquidos gerados durante o processo fermentativo. As amêndoas foram cobertas com folhas de bananeira. Realizou-se de $24 \mathrm{~h}$ em $24 \mathrm{~h}$ o revolvimento da massa, sendo o processo fermentativo de 7 dias (168h).

A secagem das amêndoas foi efetuada após o termino da fermentação, onde se utilizou o método de secagem artificial em temperatura de $70{ }^{\circ} \mathrm{C}$ até atingir $8 \%$ de umidade.

Após a secagem realizou-se a prova de corte por meio de um corte longitudinal nas amêndoas. 
Avaliou-se a qualidade em função do grau de fermentação, considerando a coloração e a compartimentação dos cotilédones. Foram avaliadas 100 amêndoas de cupuaçu em triplicata. A avaliação foi realizada seguindo os parâmetros estabelecidos para o cacau, conforme a Instrução Normativa n ${ }^{\circ} 57$ de 12 de novembro de 2008 do Diária Oficial da União.

O processo de torração foi realizado com o auxílio do forno industrial com circulação de ar. As amêndoas foram torradas colocadas no forno préaquecido a $150^{\circ} \mathrm{C}$ por $1 \mathrm{~h}$ e 30 minutos, onde foram feitos revolvimentos das amêndoas a cada 30 minutos.

\section{Caracterização físico-química}

Realizou-se a biometria das sementes, onde se avaliou as dimensões (largura, espessura e comprimento) utilizando-se paquímetro digital e a massa da semente foi determinada na balança analítica SHIMADZU modelo AY220. As dimensões foram expressas em milímetros ( $\mathrm{mm}$ ) e o peso em gramas (g), sendo realizada a medição de 100 sementes em triplicata, com auxílio de um paquímetro digital.

A temperatura foi determinada com o auxílio de um termômetro digital.

As análises de $\mathrm{pH}$, acidez total, hidroximetilfurfural (HMF) e cinzas foram determinadas conforme a metodologia do instituto Adolf Lutz (2008).

As análises de sólidos solúveis, lipídeos totais, proteínas (método de micro-Kjeldah) e umidade foram realizados pelas normas da AOAC (2005).

A determinação de açúcares foi realizada pela metodologia de DNS, utilizando o reagente ácido 3,5 dinitrossalićlico, sendo feita uma curva padrão de glicose em diferentes concentrações $(y=4,9579 x+$ 0,128; $\left.\mathrm{R}^{2}=0,999\right)$, lendo no espectrofotômetro no comprimento de onda de $540 \mathrm{~nm}$, seguindo a metodologia de Maldonade et al. (2008).
A determinação de alcaloides baseou-se nos princípios de Shufen et al., (1990), onde preparou-se uma curva padrão de cafeína $\left(\mathrm{y}=0,0453 \mathrm{x}+0,0184 ; \mathrm{R}^{2}=\right.$ $0,9923)$ em clorofórmio, no comprimento de onda de $276 \mathrm{~nm}$ e uma curva de teobromina $(\mathrm{y}=0,0541 \mathrm{x}+$ 0,$\left.0208 ; \quad R^{2}=0,9979\right) \quad$ em água acidificada, no comprimento de onda de $272.2 \mathrm{~nm}$.

A Determinação de macro e micro nutrientes foi realizada segundo a metodologia da Embrapa (2009), onde as amostras passaram por um sistema de digestão (digestão da amostra utilizou-se ácido nítrico e ácido perclórico, na proporção de 3:1.). As determinações de cálcio (Ca), magnésio $(\mathrm{Mg})$, ferro $(\mathrm{Fe})$, zinco $(\mathrm{Zn})$, cobre $(\mathrm{Cu})$ e manganês $(\mathrm{Mn})$, foram determinados por espectrometria de emissão atômica por plasma de microondas (MP-AES - Agilent Technologies - 4200). No caso do sódio $(\mathrm{Na})$ e o potássio $(\mathrm{K})$ foram quantificados por fotometria de chama (Quimis - Q498M2), enquanto que o fósforo (P), por espectrofotometria, com amarelo de vanadato (Biospectro - SP - 220).

\section{Caracterização de compostos bioativos}

A determinação de vitamina $C$ foi quantificada pelo método de titulação utilizando o DCFI (2,6 dicloroindofenol) conforme a metodologia da AOAC (2005).

O extrato utilizado para determinar fenólicos, flavonoides e a capacidade antioxidante foi elaborado pesando cerca de 5 gramas de amostra, adicionou-se com a solução de metanol a 50\% e acetona a 70\% na proporção de 1:1. Em seguida levou-se para agitação, a qual permaneceu por uma hora, em seguida foi realizado a centrifugação e coletado o sobrenadante que foi utilizado para as análises.

A determinação do teor de fenólicos totais seguiu conforme a metodologia de Singleton et al., (1999), onde utilizou-se o reagente Follin-Ciocalteu, 
sendo lido no comprimento de onda de $750 \mathrm{~nm}$, tendo como base uma curva padrão de ácido gálico ( $\mathrm{y}=$ $\left.0,0089 x+0,0848 ; R^{2}=0,9878\right)$.

Os flavonoides totais foram determinados segundo os princípios de Meda et al. (2005) e Ahn et al. (2007), como base em uma curva padrão de quercitina $\left(y=0,0283 x-0,0164 ; R^{2}=0,9985\right)$ no comprimento de onda de $415 \mathrm{~nm}$.

\section{Capacidade antioxidante}

A atividade antioxidante ABTs foi determinada segundo Kuskoski et al. (2004). Preparou-se uma curva padrão de trolox $\left(y=-0,0004 x+0,6227 ; R^{2}=0,9977\right) e$ as amostras foram lidas em $754 \mathrm{~nm}$ após 7 minutos de reação, sendo o resultado expresso em $\mu$ Mtrolox/g.

Aplicou-se também o método do DPPH, idealizado por Mensor et al., (2001), o qual é baseado na captura do radical DPPH (2,2-difenil-1- picrilhidrazil) por antioxidantes, produzindo um decréscimo da absorbância a $520 \mathrm{~nm}$. Realizou-se uma curva padrão de DPPH $\left(0,0138 x-0,0087 ; R^{2}=0,9968\right)$, onde foi determinado o teor de $\mathrm{EC}_{50 \%}$ em g de amostra / g de DPPH.

\section{Determinação da atividade enzimática}

Foram realizados diferentes extratos enzimáticos da semente de cupuaçu, onde realizou-se diversas cinéticas das enzimas polifenoloxidase (PPO) e peroxidase (POD), variando a concentração do substrato, solução tampão $(50 \mathrm{mM}$ e $100 \mathrm{mM})$, diferentes pHs $(5,5 ; 6,0 ; 6,5 ; 7,0)$ e temperaturas $\left(20^{\circ} \mathrm{C}\right.$, $30^{\circ} \mathrm{C}, 40^{\circ} \mathrm{C}, 50^{\circ} \mathrm{C}, 60^{\circ} \mathrm{C}, 70^{\circ} \mathrm{C}$ e $\left.80^{\circ} \mathrm{C}\right)$. O substrato catecol foi usado com diferentes concentrações sendo de 50, 55, 60, 65, 70 e $75 \mathrm{mM}$ para polifenoloxidase (PPO). Enquanto que para peroxidase (POD) foi utilizado o substrato guaiacol a 16.5, 17.5, 18.5, 19.5, 20.5 e $21.5 \mathrm{Mm}$ e solução de peroxido de hidrogênio 1:8 (3 mmol L-1) em tampão fosfato pH 6,0.
O extrato enzimático foi preparado com 20 gramas de amostra triturada e adicionou-se $100 \mathrm{ml}$ de solução tampão fosfato de sódio com uma grama de PVP (polivinilpirrolidona), em seguida, realizou-se agitação por um hora em banho de gelo. Realizou-se a separação das fases da amostra na centrifuga a qual se aproveitou o sobrenadante e armazenou em frasco âmbar a $-4^{\circ} \mathrm{C}$, para ser usada com fonte enzimática para as análises.

A atividade da peroxidase presente no extrato bruto da semente de cupuaçu foi determinada por meio do método espectrofotométrico (UV/VIS, Femto 700), utilizando-se o guaiacol como substrato. Em um tubo contendo $1760 \mu \mathrm{L}$ de solução tampão fosfato, foram adicionados $175 \mu \mathrm{L}$ de guaiacol e $14 \mu \mathrm{L}$ de peróxido de hidrogênio $\left(3 \mathrm{mmol} . \mathrm{L}^{-1}\right)$ com $50 \mu \mathrm{L}$ de extrato. Durante 30 em 30 segundos foi medida de reação formada até a estabilização da atividade enzimática, a absorbância do tetraguaiacol formado foi medida em $470 \mathrm{~nm}$.

A atividade enzimática da polifenoloxidase foi determinada por meio do método espectrofotométrico, utilizando o substrato catecol. O meio reacional foi composto por $50 \mu \mathrm{L}$ do extrato enzimático, $250 \mu \mathrm{L}$ de catecol, e $1700 \mu \mathrm{L}$ de solução tampão fosfato de sódio em um tubo. A velocidade da reação foi seguida em 420 nm, com leituras a cada 30 segundos até estabilização da atividade da enzima.

Tanto a peroxidase quanto a polifenoloxidase foram calculadas segundo Vieira et al., (2003) e Fernandes et al., (2007), onde uma unidade de atividade foi definida como a quantidade de enzima que provoca um aumento na absorbância de 0,001 unidades por minuto

As quantificações das proteínas totais nos extratos foi realizada empregando-se a metodologia descrita por Bradford (1976), onde preparou-se uma curva padrão de BSA (soro albumina) ( $y=0,0328 x-$ 0,009; $\left.\mathrm{R}^{2}=0,9998\right)$ com uma solução azul brilhante de 
commassie, sendo lido em $595 \mathrm{~nm}$ após 5 minutos de reação.

A determinação da atividade especifica da PPO e POD foi calculada pela razão da atividade da enzima $(\mathrm{U} / \mathrm{ml})$ e o teor de proteína total $(\mathrm{mg} / \mathrm{ml})$.

Foi determinada por meio da velocidade de reação do substrato, em período de 10 minutos a velocidade máxima de reação (Vmáx) e a constante de Michaelis-Menten ( $\mathrm{Km})$, verificando o comportamento do guaiacol e do catecol com as enzimas peroxidase e polifenoloxidase, respectivamente, sendo calculados utilizando-se o princípio de Linewever \& Burk (1934).

Todas as análises foram realizadas em triplicata, onde tirou-se a média e o desvio padrão com intervalo de confiança de 98\%, utilizando o soft Statistica 7.0.

\section{RESULTADOS E DISCUSSÃO}

$\mathrm{Na}$ tabela 01 estão os resultados encontrados na biometria das sementes utilizadas para realizar a fermentação.

Tabela 01. Biometria das sementes de cupuaçu.

\begin{tabular}{c|ccc}
\hline Análise & Média & Máximo & Mínimo \\
\hline Espessura $(\mathrm{mm})$ & $12,40 \pm 1,99$ & 17,78 & 8,55 \\
Comprimento $(\mathrm{mm})$ & $27,37 \pm 2,39$ & 34,68 & 21,27 \\
Largura(mm) & $22,3 \pm 1,6$ & 26,3 & 19,10 \\
Peso (grama) & $6,02 \pm 0,78$ & 7,69 & 4,43 \\
\hline
\end{tabular}

Ao analisar os resultados na tabela 01 , percebese que as sementes de cupuaçu provenientes da comunidade de Vila Fortaleza apresentaram dimensões semelhantes ao do intervalo encontrado por Souza (2007), o qual encontrou de 20 a $30 \mathrm{~mm}$ de comprimento, 20 a $25 \mathrm{~mm}$ de largura e 10 a $18 \mathrm{~mm}$ de espessura, com peso de 4 a 7 gramas, ao analisar variedades de cupuaçu.

Nos gráficos 01, 02, 03 e 04 mostram os comportamentos das análises de ${ }^{\circ}$ Brix, $\mathrm{pH}$, Temperatura e $\%$ de acidez total, respectivamente.

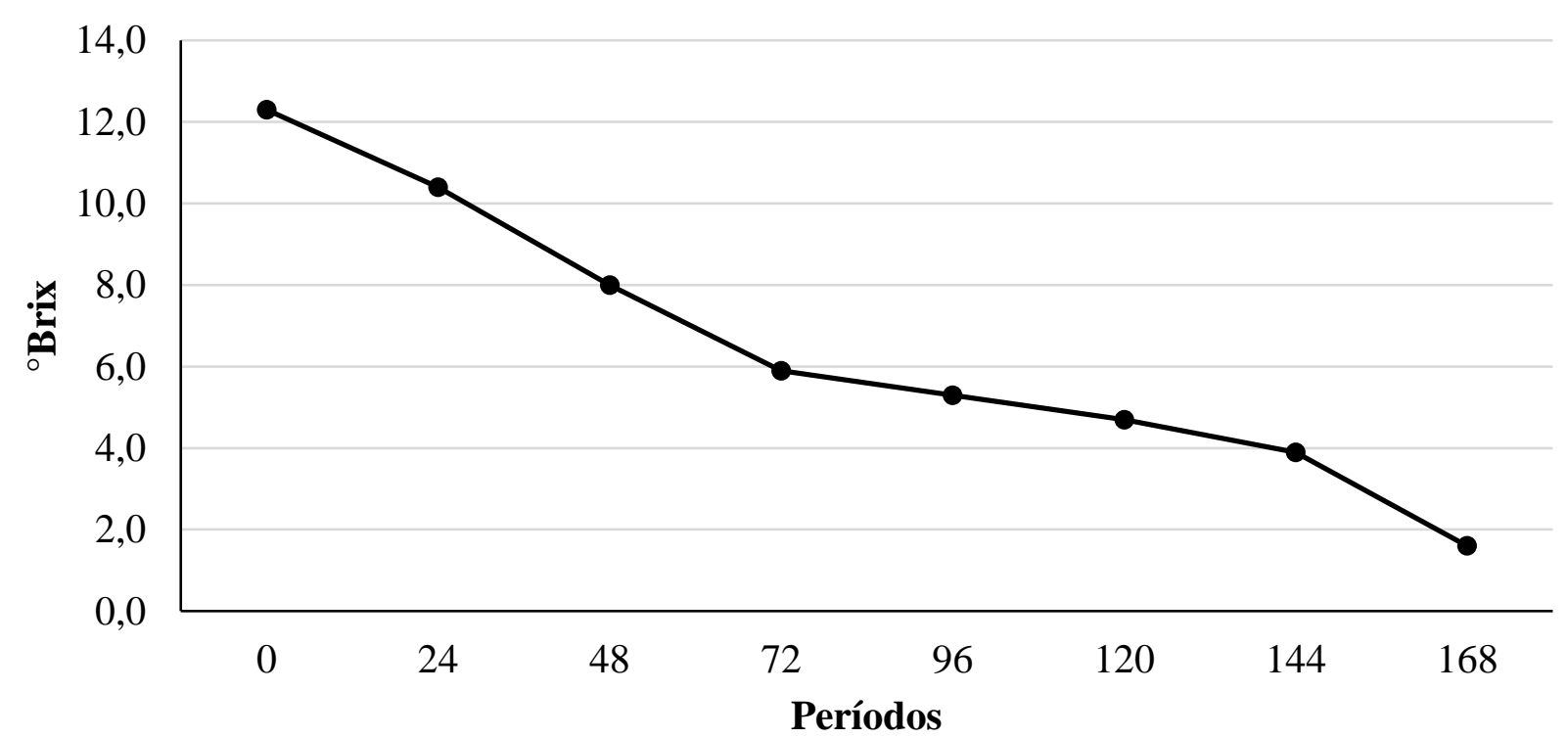

Gráfico 01. Degradação dos ${ }^{\circ}$ Brix durante o processo de fermentação. 


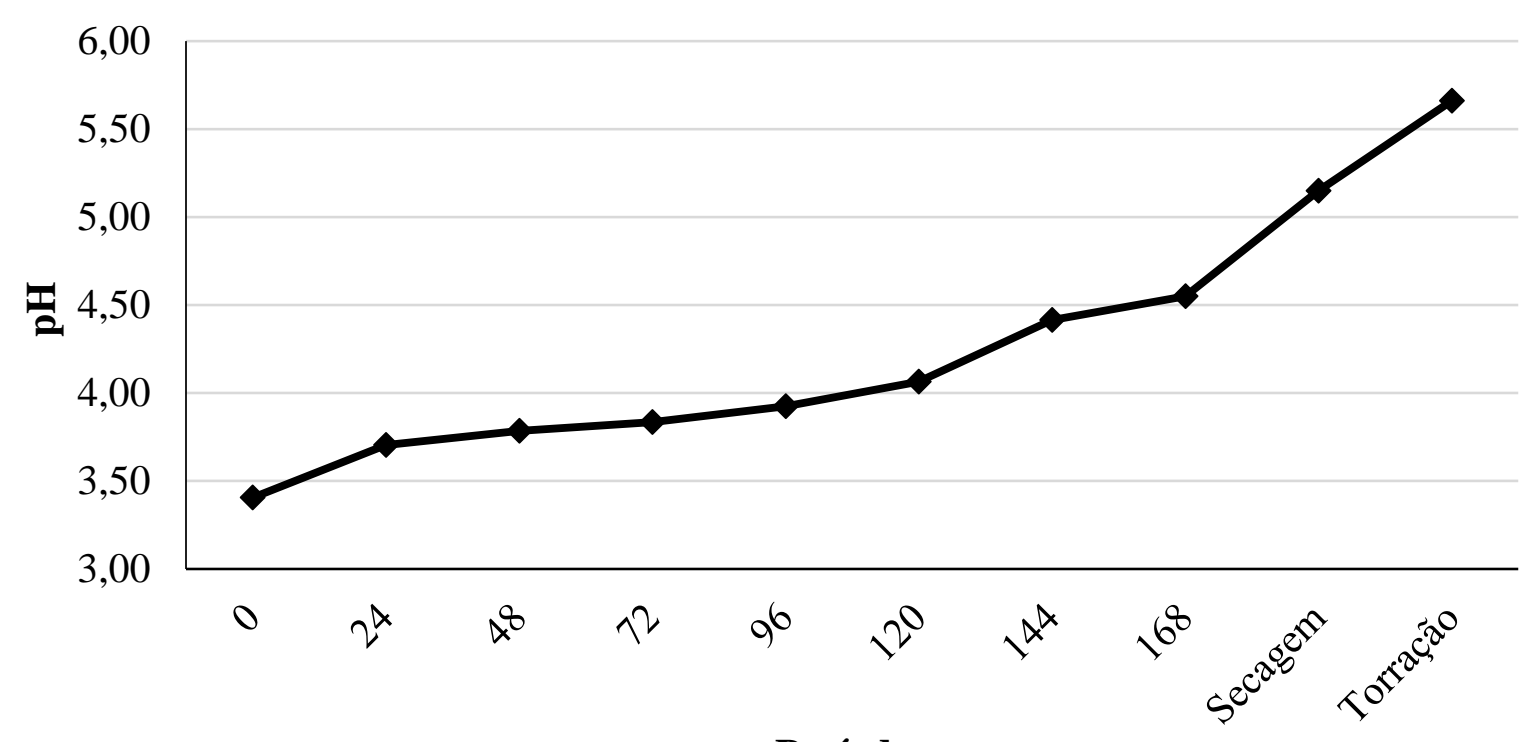

Períodos

Gráfico 02. Comportamento do pH das sementes de cupuaçu durante a fermentação, secagem e torração.

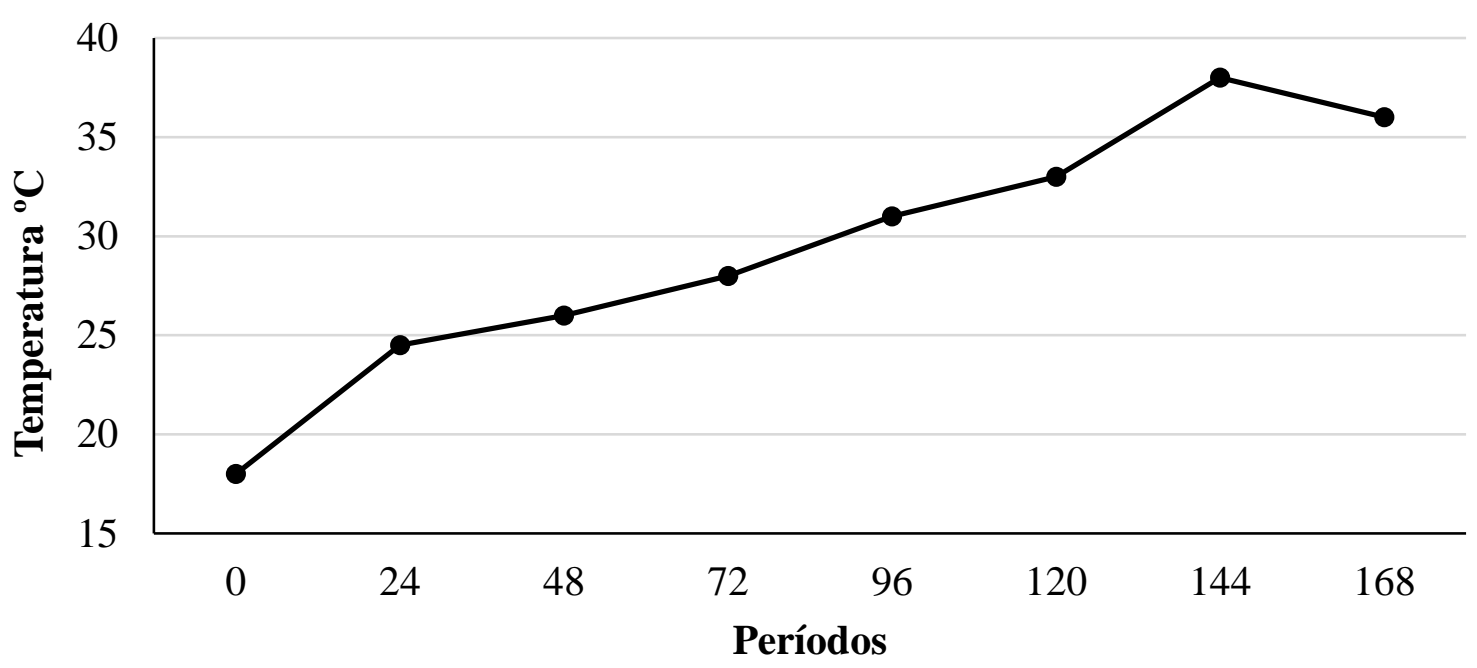

Gráfico 03. Comportamento da temperatura durante a fermentação.

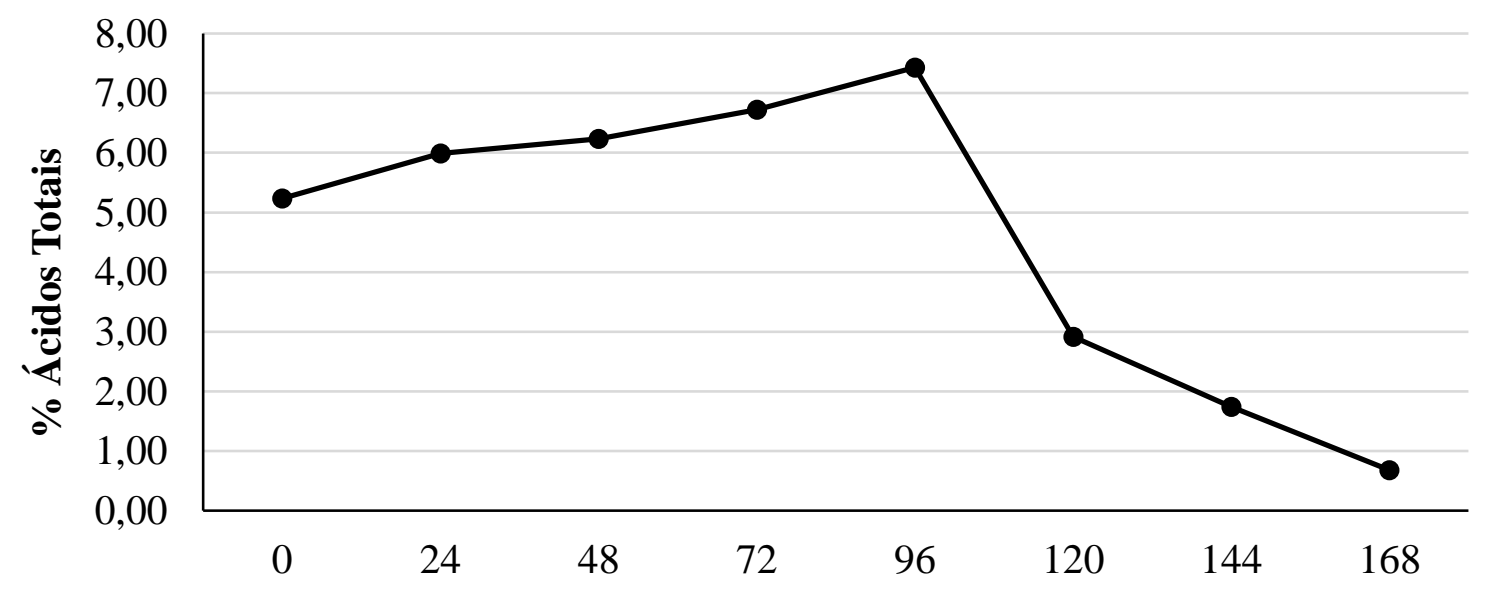

\section{Períodos}

Gráfico 04. Comportamento da \% acidez total durante o processo fermentativo. 
O comportamento dos gráficos 01, 02, 03 e 04 é explicado pelo fato da fermentação apresentar dois momentos distintos, sendo o primeiro a ação de leveduras que se propagam em virtude do teor de açúcares disponivel, o $\mathrm{pH}$ ser ácido e um ambiente predominantemente anaeróbico, o que confere meio microbiano adequado para esses tipos de microrganismo. Essa primeira fase irá resultar num começo da diminuição do ${ }^{\circ}$ Brix e um aumento na acidez, desta forma, criando um ambiente adequado para o desenvolvimento de bactérias acéticas e láticas. Essa elevação da acidez é decorrente de haver a presença, mesmo que fraca, de bactérias láticas que produziram o ácido lático e a produção de ácidos acéticos das bactérias acéticas (ZAMALLOA, 1994; MATTIETTO, 200; SCHWAN \& WHEALS, 2004).

Pode-se observar no gráfico 01, a diminuição dos ${ }^{\circ}$ Brix com redução de $87 \%$ dos açucares solúveis, enquanto que no gráfico 04 houve um aumento na acidez, desta forma criando um ambiente adequado para o desenvolvimento de bactérias acéticas e láticas.

A temperatura (gráfico 03), irá aumentando pela ação exotérmica que as leveduras apresentam no desenvolvimento $\mathrm{e}$, principalmente, pela ação das bactérias acéticas que consomem o etanol e geram calor e $\mathrm{CO}_{2}$.

Zamalloa (1994) ressalta que a temperatura no mosto fermentativo é um bom indicativo para a qualidade da mesma. Ainda destaca que caso o aumento da temperatura seja muita lenta afetará na qualidade das amêndoas, gerando sementes germinadas e mal fermentadas, porém, caso o aumento seja muito intenso, acabará afetando na atividade das enzimas endógenas e exógenas que iram atuar na semente gerando as características do chocolate.

Outros autores destacam a quantidade de sementes utilizadas no processo fermentativo, fator que influencia de maneira que potencialize a temperatura, a quantidade de microrganismo e os resultados obtidos no final da fermentação, além de observarem que a fermentação do cupuaçu pode levar de 5 a 7 dias dependendo da quantidade do mosto (NAZARÉ et al., 1990; COHEN et al., 2005; CASTRO,, 2010), no trabalho presente a fermentação durou 7 dias e a temperatura foi aumentando até o 144 horas, obtendo a temperatura máxima como se pode observar no gráfico 03.

Biehl \& PASSERN (1982), Lopes (2000) e Mattietto (2001) relatam que as amêndoas fermentadas e secas que apresentam $\mathrm{pH}$ inferior a 4,5 possuem um baixo potencial na formação do sabor de chocolate, enquanto que valores de $\mathrm{pH}$ acima de 5,0 apresentam um potencial significativamente elevado, um dos motivos pela faixa abaixo de 4,5 é explicado pela ineficiência da fermentação ou problemas obtidos durante a secagem gerando valores baixos de $\mathrm{pH}$. A fermentação deste trabalho apresentou um grande potencial, visto que o $\mathrm{pH}$ após a secagem ultrapassou a faixa de 5,0 .

Nas pesquisas de Mattietto (2001) acerca da fermentação do cupuaçu, observou que o $\mathrm{pH}$ dos cotilédones de cupuaçu começou com 6,3 e houve uma redução para 5,72, em virtude da entrada de compostos ácidos durante a fermentação. No caso da testa, ocorre o contrário, apresenta elevação de 3,35 para 6,22, semelhante ao encontrado no gráfico 02 , ocasionada provavelmente pela hidrólise proteica, no interior dos cotilédones, com liberação dos compostos para o meio externo.

No gráfico 05, encontra-se a degradação dos compostos fenólicos durante a fermentação do cupuaçu, secagem e torrefação. 


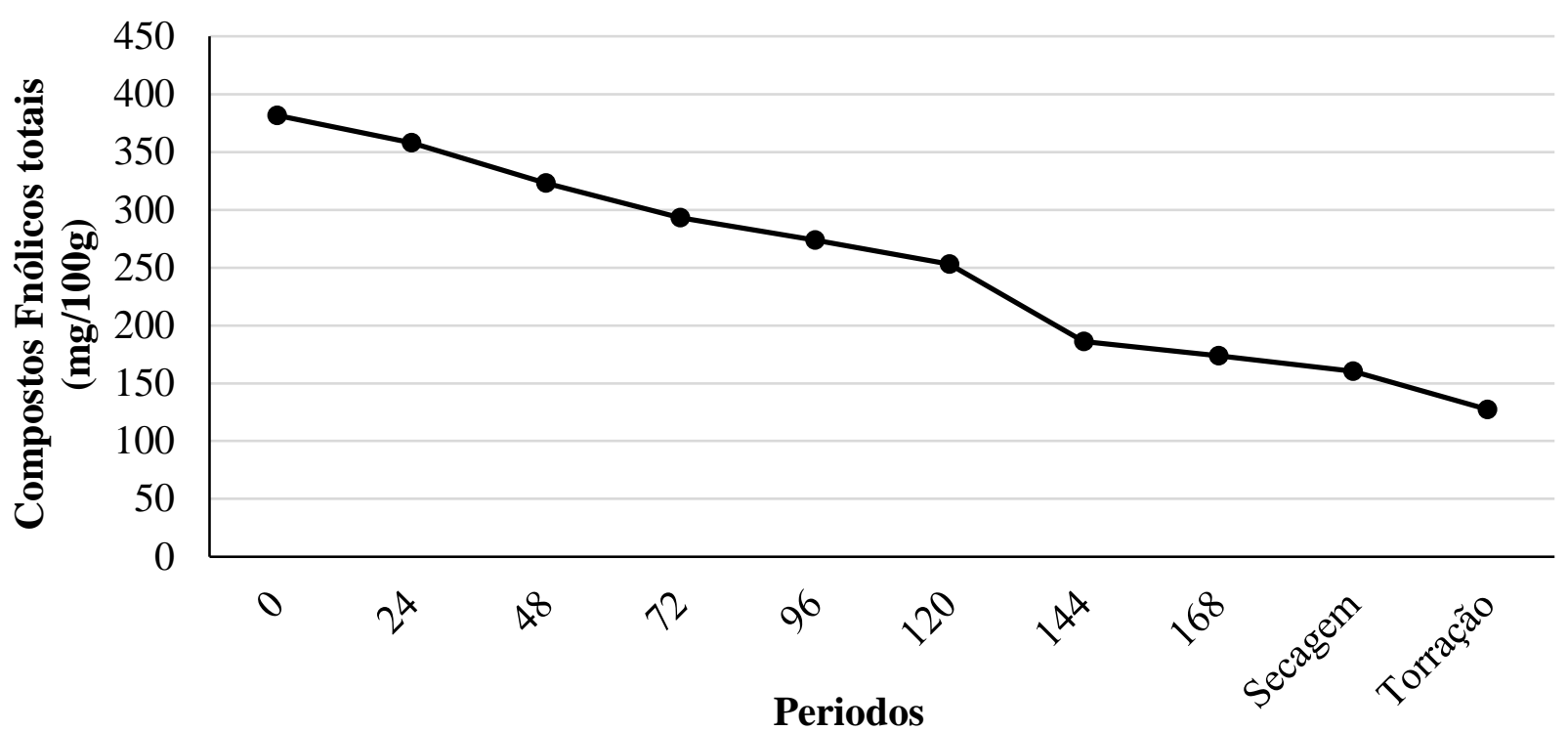

Gráfico 05. Degradação dos compostos fenólicos (mg/100g em base seca) durante a fermentação, secagem e torração.

Com base nos dados do gráfico 05 , nota-se que durante a fermentação, secagem e torração das sementes de cupuaçu, houve uma diminuição dos compostos fenólicos totais, obtendo uma variação de 381,23 para $127,24 \mathrm{mg} / 100 \mathrm{~g}$, o que indica uma boa fermentação, visto que estes substratos reagiram com as enzimas presentes e provocaram o escurecimento enzimático, além de auxiliar no escurecimento não enzimático durante o beneficiamento da amêndoa do cupuaçu.

Assim como no cupuaçu o cacau possui um conteúdo de compostos fenólicos nas sementes. Ao passar pelo processamento de fermentação, secagem e torração perdem boa parte desses compostos fenólicos, o que é favorável, pois diminuía adstringência e o amargor (LOPES, 2000; MATTIETTO, 2001; EFRAIM et al., 2010).

Pugliese (2010) observou a perda de compostos na fermentação de sementes de cupuaçu com diminuição dos compostos fenólicos, flavonoides, proantocianidinas oligoméricas e atividade antioxidante em sementes de cupuaçu após a fermentação e secagem.
A concentração da degradação dos polifenóis é variável, no caso do cacau estudos relatam perdas de até 90\% dos polifenóis durante o processo de beneficiamento do cacau (RUSCONI \& CONTI, 2010). Enquanto que neste trabalho o valor das perdas dos polifenóis chegou a ser de $66 \%$ bem próximo do valor encontrado por Toro et al., (2015), que encontraram uma redução de $70 \%$ dos compostos fenólicos durante todo o processamento do cupuaçu até a amêndoa torrada.

A temperatura e tempo utilizados durante o processo de secagem e torração deste trabalho influenciou no escurecimento do cotiledôneo, resultando na diminuição dos compostos fenólicos, pois, no processo de secagem a redução do teor de compostos fenólicos é atribuída às reações de escurecimento enzimático e não enzimático. $\mathrm{O}$ escurecimento enzimático é provocado, principalmente, pela ação de enzimas (polifenoloxidase e peroxidase) que encontram condições ideais nessa etapa para sua atividade, porém, dependendo da temperatura utiliza nesse processamento influenciará na atividade das enzimas. Enquanto, que o escurecimento 
não enzimático é decorrente da polimerização das quinonas resultantes e da acumulação de compostos insolúveis (EFRAIM et al., 2011).

Quando se compara a perdas desses polifenóis da secagem com os da torração, as porcentagens de perdas podem ser maiores, pois segundo Misnawi et al. (2004), relatam que dependendo da forma como ocorre essa torrefação, sendo o binômio tempo e temperatura utilizado, afetara a quantidade de degradação dos polifenóis.

No gráfico 06, nota-se o comportamento dos flavonoides durante o processo fermentativo, secagem e torrefação

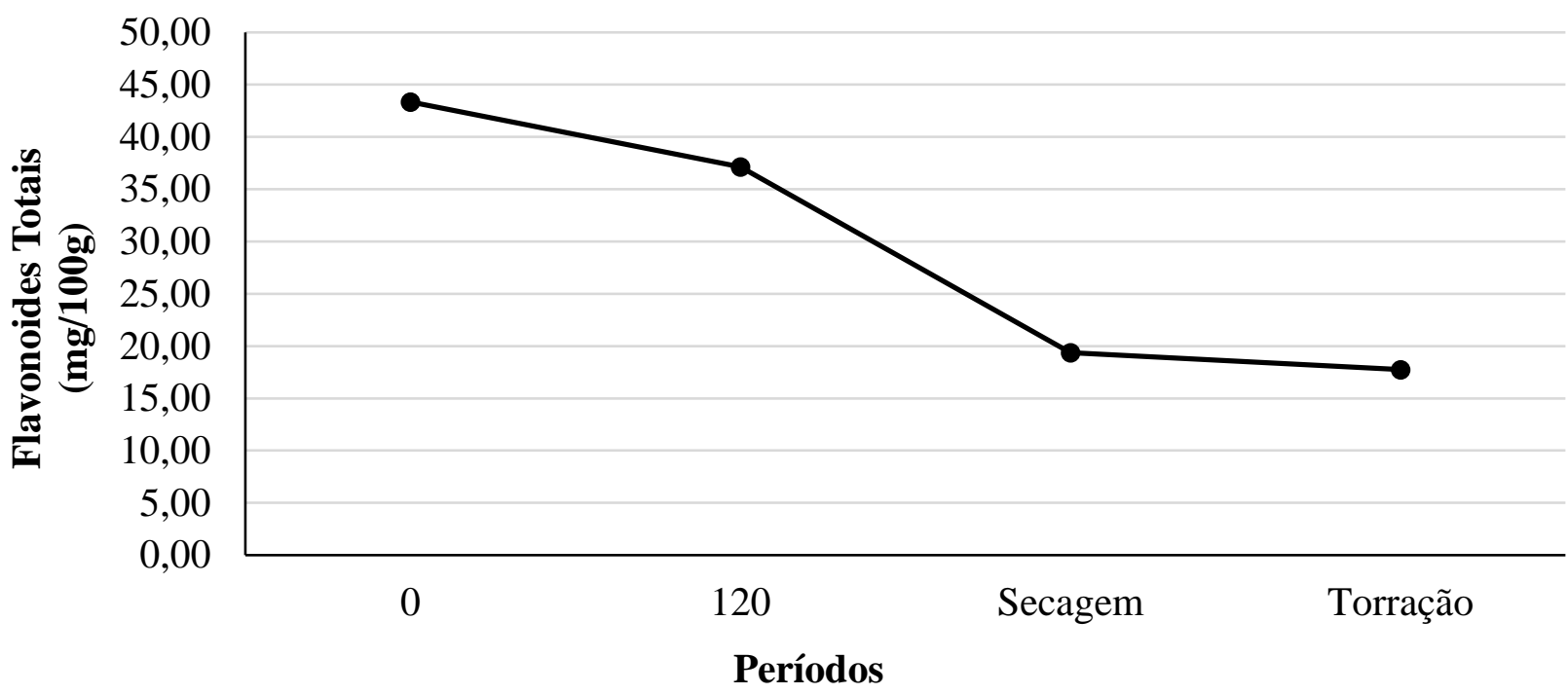

Gráfico 06. Degradação dos flavonoides totais em (mg/100 gramas de base seca) durante a fermentação, secagem e torração.

Pode-se observar no gráfico 06 uma grande degradação dos flavonoides durante todo o analisar flavonoides presentes na fermentação do beneficiamento. Destaca-se uma grande redução nos períodos da secagem e torração, pois segundo Efraim et al., (2011), nessas etapas há o aumento na difusão do oxigênio na massa de amêndoas, promovendo a oxidação dos flavonóis, além da ação da temperatura utilizada no processo que influenciará nas perdas destes compostos.

Ressalta-se que nesta pesquisa apresentou uma perda de $41 \%$ dos flavonoides totais, variando de 92 para 38,25 mg/100g quando comparado o inicial e final, perda que foi percebida também por Gruber (2010) ao cupuaçu.

Yang et al (2003) perceberam que alguns dos flavonoides encontrados no cacau, como a cianidina, não são encontrados no cupuaçu, e alguns dos flavonoides encontrados no cupuaçu, como a Theograndina I e II, não são encontrados no cacau, porém existem grandes semelhanças na composição de flavonoides entre esses frutos. Tais similaridades, somadas à proximidade filogenética destes frutos de mesmo gênero, sugerem semelhanças no metabolismo secundário destas espécies (ORTEGA et al., 2008).

No gráfico 07, observa-se a degradação do ácido ascórbico durante a fermentação. 


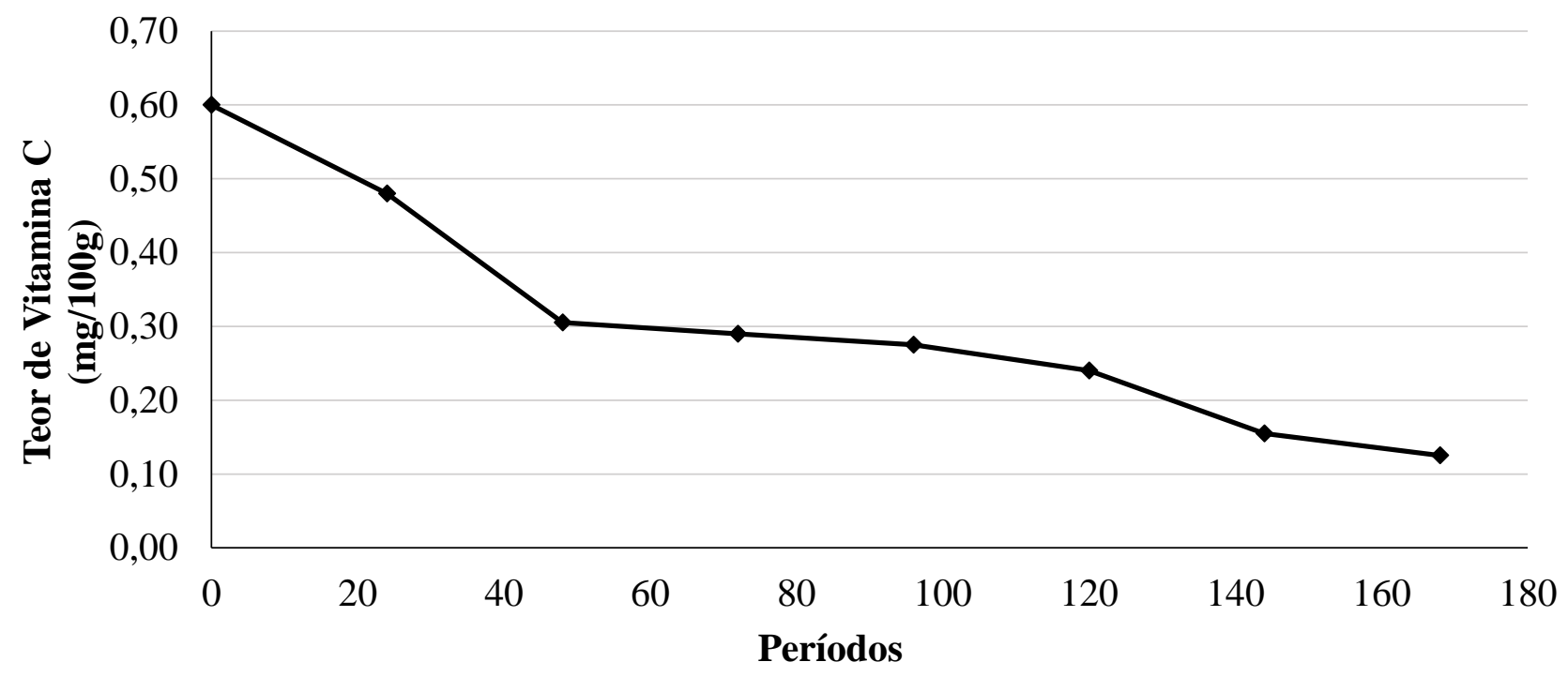

Gráfico 07. Degradação do teor de vitamina C (mg/100g) durante a fermentação.

A perda de cerca de $79 \%$ do teor de ácido ascórbico (gráfico 07) durante a fermentação, pode ser explicada decorrente deste grupo ser um dos principais antioxidantes contidos nos vegetais, pois possui intuito de prevenir o escurecimento e outras reações oxidativas, podendo agir de duas maneiras. Sendo a primeira atuando diretamente na enzima, complexando o cobre do grupo prostético da PPO, resultando na inibição da atividade enzimática. A outra possibilidade é a redução das quinonas a sua forma anterior de fenóis, desta forma, impedindo a formação dos pigmentos escuros (SAPERS et al., 1989; PAULA, 2007).

Ressalta-se que a redução das quinonas aos seus precursores fenólicos leva à oxidação irreversível do ácido ascórbico e à formação de ácido dehidro ascórbico sem atividade inibitória (MARSHALL et al., 2000).

$\mathrm{Na}$ tabela 02 encontra se a determinação da atividade antioxidante em base seca, nos períodos da fermentação, secagem e torração.

Tabela 02. Determinação da atividade antioxidante na fermentação, secagem e torração.

\begin{tabular}{c|cc}
\hline Período & ABTS $(\boldsymbol{\mu M t r o l o x} / \mathbf{g})$ & DPPH $(\mathrm{g}$ amostra/g de DPPH) \\
\hline $0 \mathrm{~h}$ & $33,64 \pm 0,79$ & $753,05 \pm 26,8$ \\
Secagem & $24,22 \pm 0,43$ & $1724,45 \pm 24,4$ \\
Torração & $22,63 \pm 0,30$ & $2701,15 \pm 22,98$ \\
\hline
\end{tabular}

Ao observa os dois métodos descritos na tabela 02, nota-se uma redução da atividade antioxidante, sendo uma redução de cerca $32,73 \%$ na atividade ABTS, enquanto que na de DPPH a diminuição foi de $72 \%$ em relação ao DPPH. Essa perda é consequência de diversos fatores desde a diminuição no teor dos compostos bioativos como fenólicos e vitamina C, que atuam em moléculas para prevenir a oxidação enzimática e não enzimática nas sementes.

Resultados semelhantes aos deste trabalho foi encontrado na pesquisa de Gruber (2010) no período de fermentação do cupuaçu.

Ao comparar o potencial antioxidante do cupuaçu com o cacau, percebe-se que o potencial antioxidante do cupuaçu pode ser interessante em 
relação a certos tipos de variedades de cacau, pois como demostra a pesquisa de Costa (2013), o qual realizou diversas fermentações de cacau, obtendo valores iniciais de 24,2 $\mu \mathrm{mol}$ Trolox/grama e finais variando de 13 a 17 $\mu$ moltrolox/grama, enquanto que nesta pesquisa o menor valor foi de 22,63 $\mu \mathrm{mol}$ Trolox/grama. No entanto, nas amostras de cacau analisadas por Salvador (2011), apresentou um teor maior na capacidade antioxidante que o encontrado nesta pesquisa, esse fato se deve pelo clima, condições de solo e principalmente pela variedade do cacau trabalhada.
Destaca-se as pesquisas de Song et al. (2010), os quais observaram uma correlação positiva entre o teor de compostos bioativos e capacidade antioxidante. Tal correlação positiva também foi percebida neste trabalho, sendo de 0,71 e 0,844 dos compostos fenólicos em relação a ABTs e DPPH, respectivamente, desta forma, mostrando que o teor de compostos fenólicos é um dos fatores que influencia na capacidade antioxidante.

No gráfico 08, observa-se o comportamento do hidroximetilfurfural durante as etapas de fermentação, secagem e torração.

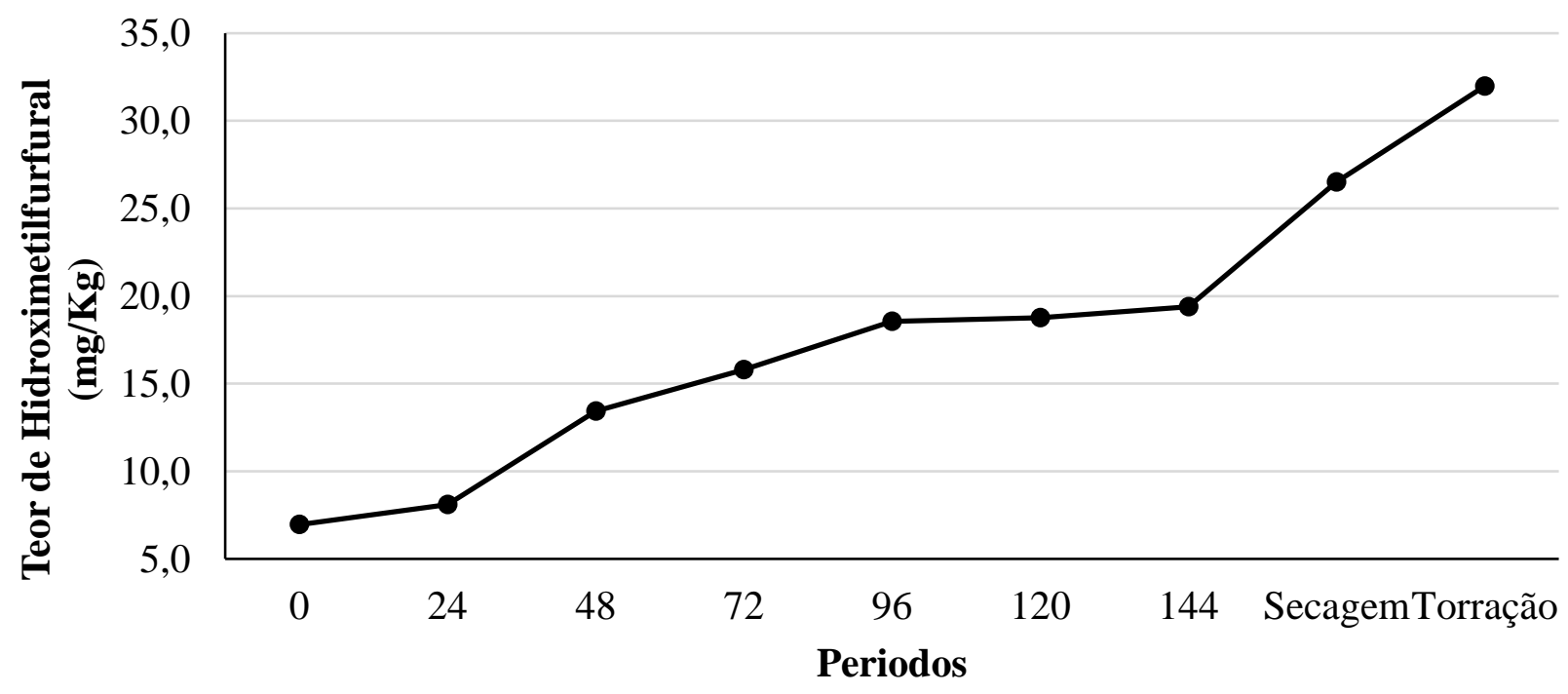

Gráfico 08. Comportamento do teor de hidroximetilfurfural (mg/Kg) durante a fermentação, secagem e torração.

Ao analisar o gráfico 08, percebeu-se um aumento na quantidade do hidroximetilfurfural formado desde o início $(6,94 \mathrm{mg} / \mathrm{Kg})$ até a amêndoa torrada $(33,87 \mathrm{mg} / \mathrm{Kg})$, sendo confirmado pela mudança visual na coloração dos cotiledôneos, que no caso da fermentação do cupuaçu vai de uma cor amarelada para um marrom intenso, como mostra a figura 01. Essa intensidade de cor e justificada no período da fermentação pela ação das enzimas, que utilizam dos substratos e geram quinonas, compostos altamente reativos que podem combinar-se entre si ou com outros componentes do meio, como, as proteínas, lipídeos, ácidos nucléicos e carboidratos, gerando produtos de condensação de alta massa molecular e cor escura, chamados de melaninas (YORUK et al., 2003; ORTOLAN, 2006).

Desta forma, em relação a coloração das sementes, o período de fermentação é predominante pela a ação das enzimas, enquanto que na secagem e torração os açúcares redutores com aminoácidos e peptídeos estão envolvidos na formação do "flavor" e coloração por veio da reação de Maillard (formação de 
quinonas), sendo responsáveis por compostos básicos

RIZZI \& BUNKE, 1998; BIEHL \& ZIEGLEDER, do aroma do chocolate (BIEHL \& PASSERN, 1982;

2003).

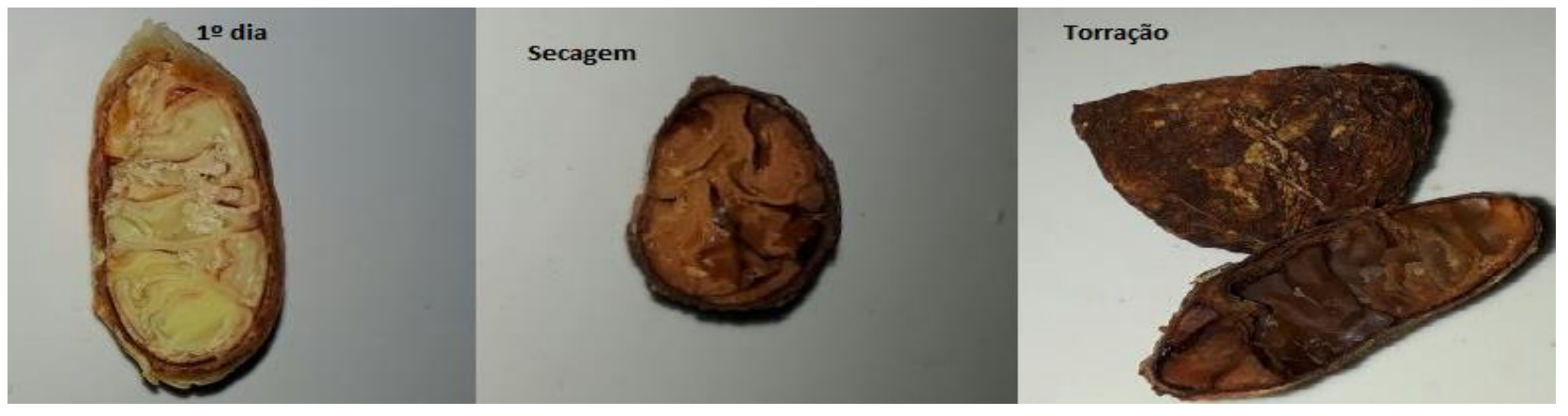

Figura 01. Coloração do cotilédone da semente de cupuaçu do início da fermentação, secagem e torração.

Com a figura 01 , percebe-se que houve o escurecimento da semente por diversas reações enzimáticas e não enzimáticas, resultando num produto final com coloração semelhante a massa de cacau.
$\mathrm{Na}$ tabela 03 encontram-se os teores de teobromina e cafeína encontrados neste trabalho durante o período de secagem e torração.

Tabela 03. Teores de teobromina e cafeína em mg/g em amêndoas após a secagem e torrefação.

\begin{tabular}{c|cc}
\hline Período & Teobromina (mg/g) & Cafeína (mg/g) \\
\hline Secagem & $10,22 \pm 0,18$ & $3,03 \pm 0,01$ \\
Torração & $9,14 \pm 0,3$ & $2,60 \pm 0,06$ \\
\hline
\end{tabular}

Com base nos resultados da tabela 03 , foi possível observar que as sementes de cupuaçu apresentam alcaloides (teobromina e cafeína), porém em quantidades inferiores ao cacau, pois segundo Lo Coco et al., (2007), as amêndoas torradas de cacau apresentaram 33,0 mg/g de teobromina e $5,6 \mathrm{mg} / \mathrm{g}$ de cafeína, enquanto que para as amêndoas de cupuaçu dos mesmos autores detectaram $0,5 \mathrm{mg} / \mathrm{g}$ de cafeína e $1 \mathrm{mg} / \mathrm{g}$ de teobromina, sendo as amêndoas de cupuaçu estudadas deste trabalho superiores aos reportados por Lo Coco et al., (2007).

Além desse fato, percebeu-se uma pequena redução nos valores dessas metilxantinas no momento da secagem para torração, sendo de 10,6\% para teobromina e 14,2\% para cafeína. Uma possível explicação para essa perda de alcaloides é devido exsudação durante a fermentação e oxidação durante a secagem e torrefação, como já se foi reportado na fermentação do cacau, contudo, a redução deste compostos é benéfica pois resulta na redução do sabor amargo do chocolate (LOPEZ \& DIMICK, 1991).

Antes da realização da fermentação, secagem e torração, foram realizados testes preliminares para determinar o parâmetro ótimo de atuação das enzimas PPO e POD, variando diversos fatores, como: concentração da solução tampão (100mM e $50 \mathrm{mM})$, pHs $(5,5 ; 6,0 ; 6,5 ; 7,0)$, temperatura $\left(20^{\circ} \mathrm{C}, 30^{\circ} \mathrm{C}, 40^{\circ} \mathrm{C}\right.$, $50^{\circ} \mathrm{C}, 60^{\circ} \mathrm{C}, 70^{\circ} \mathrm{C}$ e $80^{\circ} \mathrm{C}$ ), concentração do substrato de catecol (25, 50, 75 e $100 \mathrm{mM})$ e guaiacol $(10,16,22$, 25 e $30 \mathrm{mM})$. 
Tanto para POD quanto para PPO, observaram-se atividades enzimáticas ótimas na concentração de solução fosfato de 100 mM e pH 6. A temperatura ótima, para a polifenoloxidase foi $30^{\circ} \mathrm{C} \mathrm{e}$ $40^{\circ} \mathrm{C}$ para peroxidase.

Em relação ao substrato observou-se que para POD o guaiacol apresentou uma boa atividade enzimática entre 16 e 22 mM. Após encontrar a faixa boa de concentração do guaiacol fez-se uma nova varredura para detectar a faixa ótima para atuação da enzima, desta forma, analisaram-se as concentrações de $16.5,17.5,18.5,19.5,20.5,21.5$ e $22 \mathrm{mM}$ de guaiacol e encontrou-se que em $21.5 \mathrm{mM}$, apresentou a melhor atividade enzimática para POD.
No caso da PPO, observou-se uma boa atividade enzimática na faixa de concentração do catecol de 50 e 75 mM, em seguida, fez-se uma nova varredura para detectar a faixa ótima de atuação da enzima, a qual utilizou se de soluções de 50, 55, 60, 65, 70 e $75 \mathrm{mM}$ de catecol. A melhor atividade para enzima PPO foi na a concentração de $55 \mathrm{mM}$, sendo responsável pelo melhor desempenho em relação as demais concentrações.

Mediantes a informação dos parâmetros ótimos de ambas as enzimas, verificou se o comportamento da atividade enzimática e atividade enzimática especifica durante o processo de fermentação até a torração, como mostra o gráfico 09 e 10, para comportamento da polifenoloxidase.

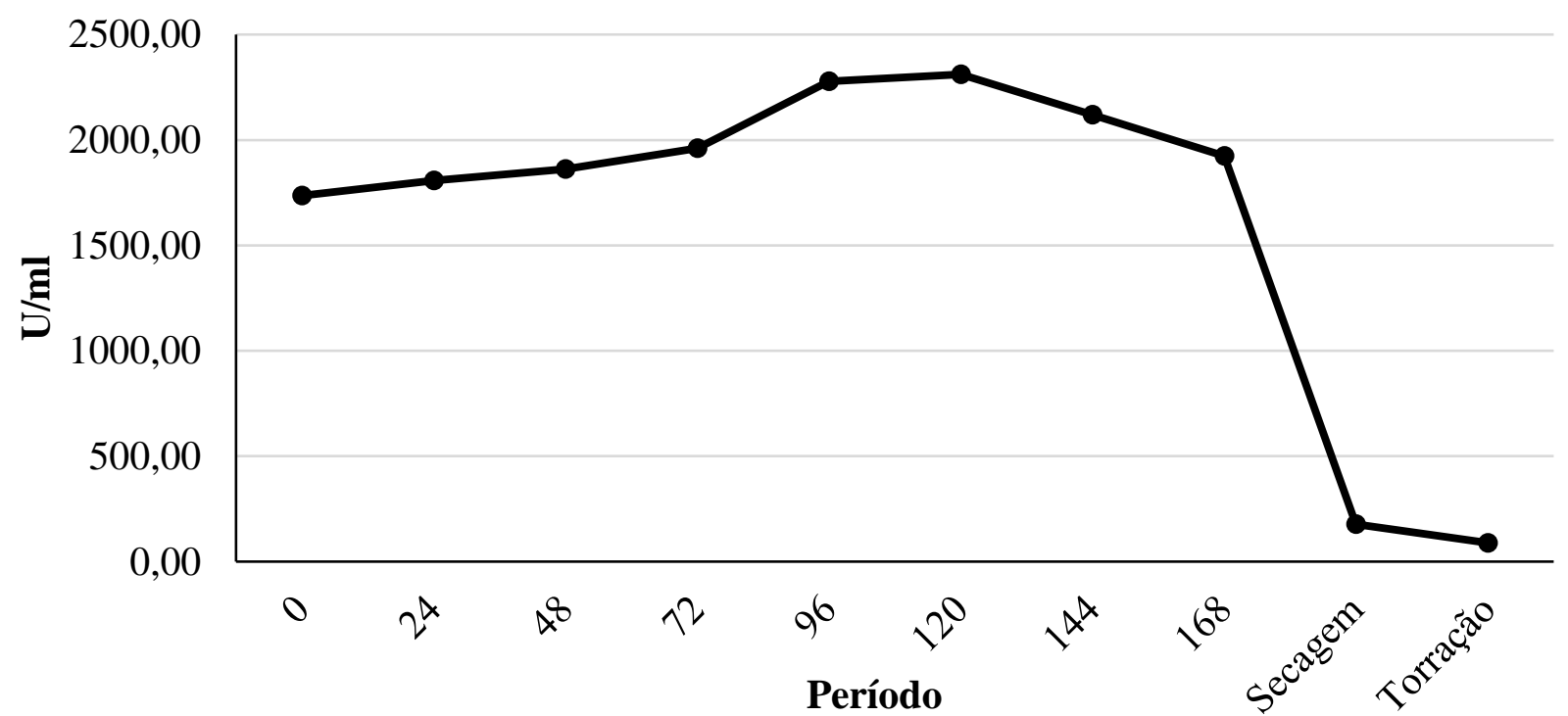

Gráfico 09. Comportamento da atividade enzimática da PPO durante a fermentação, secagem e torração. 


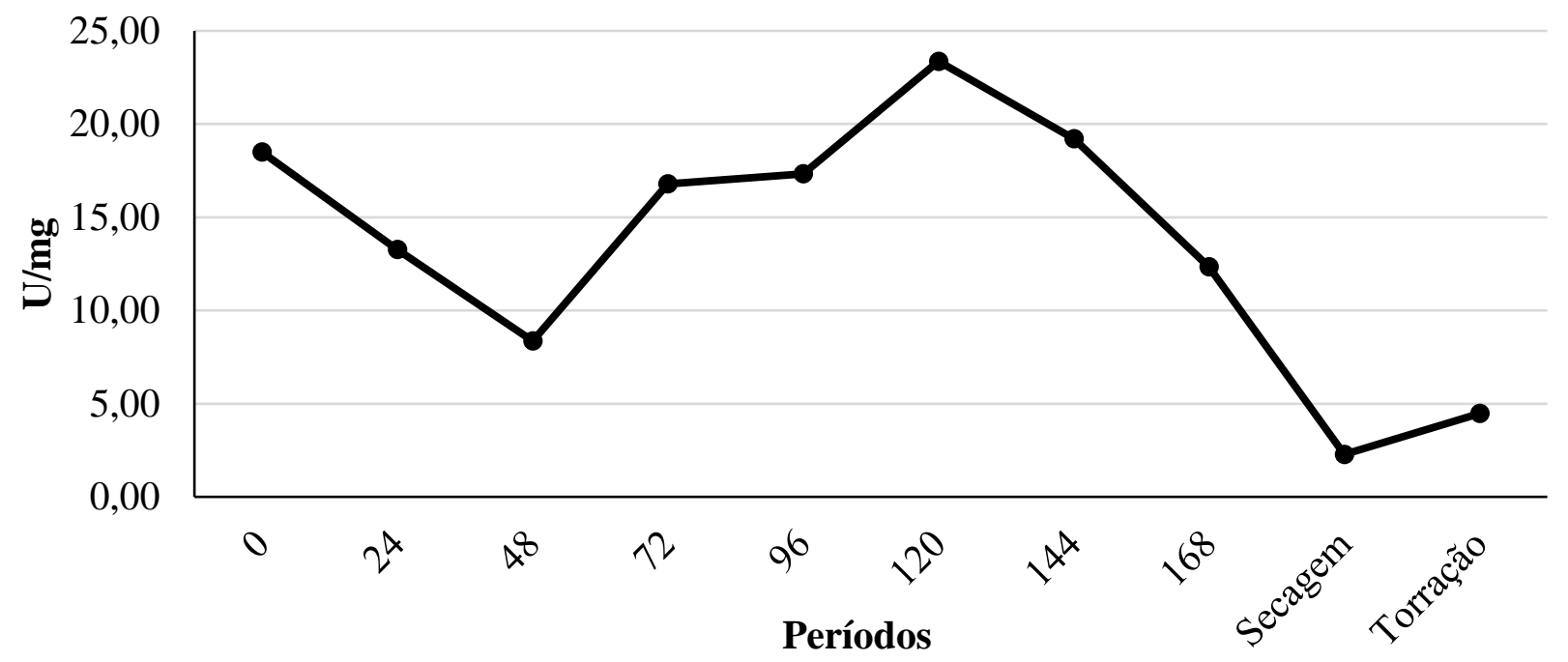

Gráfico 10. Comportamento da atividade enzimática específica da PPO durante a fermentação, secagem e torração.

Ao longo da fermentação percebeu-se um aumento gradativo da atividade enzimática e da atividade especifica da enzima, até chegar em 120 horas de fermentação, onde a atividade da enzima PPO atingiu o ápice de ação no mosto fermentativo, observando-se uma temperatura de $33^{\circ} \mathrm{C}$, valor próximo da faixa ótima detectada durante os parâmetros cinéticos da enzima.

Utilizou-se o ponto ápice (120 h) da atividade da enzima nos gráficos 09 e 10 como parâmetro de $100 \%$ de atividade, desta forma, encontra-se a redução da atividade da PPO na tabela 04 .

Tabela 04. Percentual de redução da atividade da PPO com relação a influência da temperatura.

\begin{tabular}{ccc}
\hline Período & Redução da A.E. PPO (\%) & Redução da A.E.E. PPO (\%) \\
\hline $144 \mathrm{~h}$ & 8,3 & 28,49 \\
$168 \mathrm{~h}$ & 16,7 & 32,48 \\
Secagem & 92,6 & 80,58 \\
Torração & 96,2 & 90,11
\end{tabular}

Legenda: A.E. (atividade enzimática), A.E.E. (atividade enzimática especifica).

Constatou que houve uma redução da atividade enzimática chegando a um valor de $96,2 \%$, enquanto que a atividade especifica alcançou uma redução de 90,11\% no final do processo (torrefação), esse fato é explicável, em virtude da enzima não possuir uma termoestabilidade e não apresentar condições favoráveis para atuação da enzima.

Yang (2003) ressalta a grande contribuição da formação da cor na amêndoa pela polifenoloxidase, que além de influenciar na aparência visual contribuem para o "flavor", pois reduzem a adstringência devido a oxidação de taninos.

Ademais é necessário ratificar que vários autores na literatura constataram a importância da polifenoloxidase durante a fermentação, como Soares (2001) que utilizou extratos de PPO provinda da pinha, a qual foi incorporada na fermentação do cacau. Observou um melhoramento durante a fermentação, em virtude da quantidade de enzimas que intensificou a oxidação dos compostos fenólicos e consequentemente 
reduzindo o amargo e adstringência, sendo uma opção para o melhoramento da fermentação.

O comportamento da atividade enzimática e atividade enzimática específica durante o processo de fermentação até a torração da peroxidase está descrita conforme os gráficos 11 e 12.

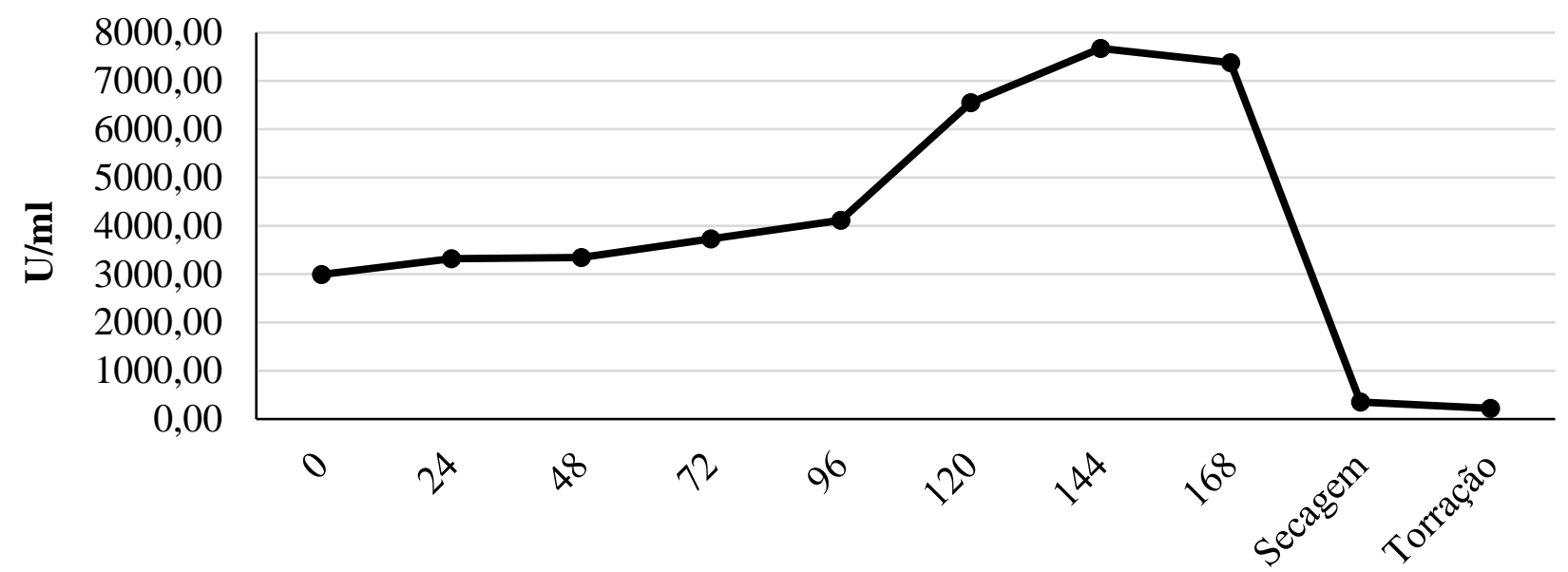

Períodos

Gráfico 11. Comportamento da atividade enzimática $(\mathrm{U} / \mathrm{ml})$ da POD durante a fermentação, secagem e torração.

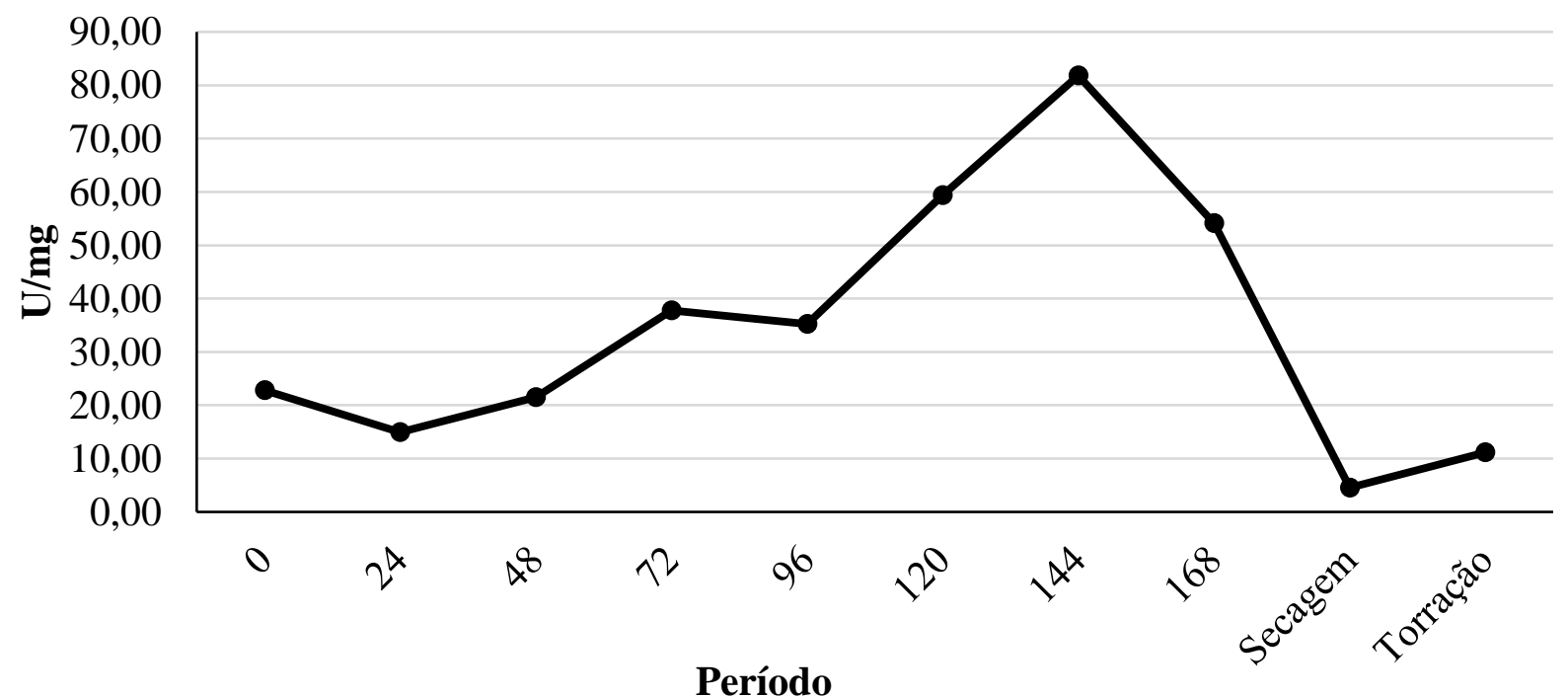

Gráfico 12. Comportamento atividade específica da POD durante a fermentação, secagem e torração.

No caso da peroxidase, observou-se um crescimento da atividade enzimática e atividade enzimática especifica ao longo da fermentação e um ápice de ação enzimática em 144 horas, como mostra o gráfico 11 e 12, onde a fermentação chegou em uma temperatura de $38{ }^{\circ} \mathrm{C}$, temperatura próxima da faixa ótima encontrada nos parâmetros cinéticos da enzima. Utilizou-se o ponto ápice em 144 h da atividade da enzima nos gráficos 11 e 12 como parâmetro de $100 \%$ de atividade, desta forma, encontra-se a redução 
da atividade da POD na tabela 05, ao comparar com as

atividades encontradas em 168h, secagem e torração.

Tabela 05. Percentual de redução da atividade da POD com relação a influência da temperatura.

\begin{tabular}{c|c|c}
\hline Período & Redução da A.E. POD (\%) & Redução da A.E.E. POD (\%) \\
\hline $168 \mathrm{~h}$ & 3,9 & 32,66 \\
\hline Secagem & 95,4 & 77,3 \\
\hline Torração & 98,4 & 90,75 \\
\hline
\end{tabular}

Legenda: A.E. (atividade enzimática), A.E.E. (atividade enzimática especifica).

Com base na tabela 05 , percebeu-se uma acentuada diminuição da atividade da POD. Tal redução pode ser explicada pelo longo período de aquecimento, diminuição na aw e apresentar um meio pouco favorável para atuação da enzima.

A redução e a elevação da atividade enzimática observadas nos gráficos 09 a 12, é influenciada por vários fatores, como, teor e disponibilidade dos fenólicos ao reagirem com as enzimas, alteração na faixa de $\mathrm{pH}$, temperatura, presença de ácidos (acético, lático) entre outros fatores. A literatura aborda fatores semelhantes aos encontrados por outros autores na fermentação do cacau (HANSEN et al., 1998; CHITARRA \& PRADO, 2002).

No estudo da fermentação da semente de cupuaçu, Garcia (2006), detectou a presença de amilases, invertases, pectinesterases, poligalacturonases, peroxidases, polifenoloxidases, proteases e lipases na fermentação e verificou que a atividade dessas enzimas começa a apresentar elevação a partir das $24 \mathrm{~h}$ de fermentação. Todas as enzimas estudadas por Garcia (2006), apresentam ótima atuação em uma faixa de pH entre 4,2 e 4,6, resultados semelhantes foram encontrados nesta pesquisa.

Apesar do pH ideal de atuação das enzimas PPO e POD serem o pH 6,0, conforme os dados da cinética enzimática, pode ocorrer a possibilidade de atuação dessas enzimas em faixas de $\mathrm{pH}$ variados, porém, não alcançando a atividade ótima para as enzimas.

Meersman et al. (2013), constatou que a fermentação não possui padrões que se permaneçam constantes, sendo diversos fatores que afetam a qualidade da fermentação desde a quantidade de sementes no mosto, padrões climáticos dentre outros fatores.

Nas tabelas 06 e 07 encontram-se os valores da constante de Michael-Mentes (Km) e Vmáx da peroxidase e polifenoloxidase, respectivamente, durante a fermentação.

Tabela 06. Valores do Km (constante de Michael-Mentes) e Velocidade máxima (Vmáx) para peroxidase.

\begin{tabular}{|c|c|c|}
\hline Período da Fermentação & Vmáx $(\mu \mathrm{M} / \mathrm{min})$ & $\mathrm{Km}(\mu \mathrm{M})$ \\
\hline 0 horas & $6,50_{x} 10^{-2}$ & 14,43 \\
\hline 72 horas & $5,06_{x} 10^{-2}$ & 7,26 \\
\hline 120 hora & $7,87 \times 10^{-2}$ & 4,23 \\
\hline 168 horas & $8,44_{x} 10^{-2}$ & 4,80 \\
\hline
\end{tabular}


Tabela 07. Valores do Km (constante de Michael-Mentes) e Velocidade máxima (Vmáx) para polifenoloxidase.

\begin{tabular}{c|cc}
\hline Período da Fermentação & Vmáx $(\boldsymbol{\mu M} / \mathbf{m i n})$ & $\mathbf{K m}(\boldsymbol{\mu M})$ \\
\hline 0 horas & $8,14_{\mathbf{x}} 10^{-3}$ & 7,81 \\
72 horas & $9,72_{\mathbf{x}} 10^{-3}$ & 1,91 \\
120 horas & $5,68_{\mathbf{x}} 10^{-3}$ & 1,24 \\
168 horas & $1,36_{\mathbf{x}} 10^{-2}$ & 5,31 \\
\hline
\end{tabular}

Ao analisar ambas as tabelas percebeu-se que com o decorrer do tempo de fermentação e o desenvolvimento da atividade da PPO e POD (gráficos 09 a 12), observou-se um aumento na velocidade máxima. No entanto, no último dia de fermentação (168 horas), como não possui condições adequadas e apresentava pouco substrato disponível, como mostra o gráfico 05 , dificultou ação das enzimas sobre o substrato, resultando numa diminuição da velocidade de reação.

Em relação a afinidade do substrato com a enzima, nota-se que tanto a POD e a PPO apresentaram elevados graus de afinidade com os substratos, valores que atingiram o ponto máxima de afinidade em 120 horas de fermentação (tabela 07), tal valor foi auxiliado ao encontrar faixas mais especificas de concentração de guaiacol e catecol, pois segundo pesquisas de Elba et al., (2008) observaram que uma saturação mais adequada dos sítios enzimáticos influencia na afinidade da enzima com o substrato.

As sementes de cupuaçu que passaram por o processo de fermentação e secagem foram avaliadas e aplicadas às normas segundo a Instrução Normativa $n^{\circ}$ 57 de 12 de novembro de 2008, a fim de caracterizar o lote das amêndoas. As amêndoas foram classificadas como amêndoas do tipo II, enquadrando-se na porcentagem de defeitos e qualidades estabelecida pela categoria.

Ressalta-se que essa normativa é para amêndoas de cacau, pois o cupuaçu não possui uma legislação estabelecida, desta forma, fez-se uma comparação com a legislação de cacau para obter um parâmetro de qualidade.

$\mathrm{Na}$ tabela 08 e 09, encontram-se os resultados obtidos da análise físico-química da amêndoa torrada.

Tabela 08. Resultados da amêndoa torrada.

\begin{tabular}{cc}
\hline Análise & Resultados \\
\hline Umidade (\%) & $8,3 \pm 0,4$ \\
Matéria seca (\%) & $91,7 \pm 0,4$ \\
Gordura (\%) & $49,15 \pm 1,1$ \\
$\mathrm{pH}$ & $5,66 \pm 0,01$ \\
Proteína (*) & $9,75 \pm 0,02$ \\
Cinzas (\%) & $2,5 \pm 0,3$ \\
Açúcares redutores (\%) & $1,21 \pm 0,02$ \\
Açúcares Total (\%) & $1,32 \pm 0,02$ \\
Açúcares não redutores $(\%)$ & $0,11 \pm 0,01$ \\
\hline
\end{tabular}

Legenda: $\left(^{*}\right)$ resultados expressos em base seca. 
Tabela 09. Composição dos macro e micro nutrientes da amêndoa do cupuaçu em base seca.

\begin{tabular}{cc}
\hline \multicolumn{3}{c}{ Macro Nutrientes } \\
\hline $\mathrm{N}(\mathrm{g} / \mathrm{Kg})$ & $17,35 \pm 0,23$ \\
$\mathrm{P}(\mathrm{g} / \mathrm{Kg})$ & $3,01 \pm 0,04$ \\
$\mathrm{~K}(\mathrm{~g} / \mathrm{Kg})$ & $8,47 \pm 0,002$ \\
$\mathrm{Na}(\mathrm{g} / \mathrm{Kg})$ & $0,14 \pm 0,001$ \\
$\mathrm{Ca}(\mathrm{g} / \mathrm{Kg})$ & $1,02 \pm 0,06$ \\
$\mathrm{Mg}(\mathrm{g} / \mathrm{Kg})$ & $2,62 \pm 0,10$ \\
\hline & \\
\hline $\mathrm{Fe}(\mathrm{g} / \mathrm{Kg})$ & Micro nutrientes \\
$\mathrm{Zn}(\mathrm{g} / \mathrm{Kg})$ & $57,63 \pm 0,59$ \\
$\mathrm{Cu}(\mathrm{g} / \mathrm{Kg})$ & $47,33 \pm 0,06$ \\
$\mathrm{Mn}(\mathrm{g} / \mathrm{Kg})$ & $31,09 \pm 0,20$ \\
\hline
\end{tabular}

Com os resultados encontrados na tabela 08 , quando comparados aos autores Carvalho et al., (2005) e Gruber (2010), observa-se que a amêndoa torrada apresenta conteúdo similar em relação a esses dois autores, porém uma quantidade inferior de lipídeos.

Em relação aos macro e micronutrientes (tabela 09), ressalta-se que amêndoa de cupuaçu apresentou teores interessantes. A presença desses elementos é um bom indicativo, já que os mesmo trazem benefícios a saúde humana, como o zinco, o qual atua na defesa antioxidante plasmática, de tal forma que inibe ou reduz a ação da NADPH-oxidase, que é uma enzima relacionada a produção de espécies reativas de oxigênio. Pode atuar também diretamente na neutralização do radical livre hidroxila, além da possibilidade de produção de metalotioninas. Além dessas possibilidades, estudos propõem que o consumo adequado de zinco pode reduzir o risco cardiometabólico e reduzir a ocorrência de eventos cardiovasculares em portadores de diabete melito tipo 2 (KINLAW et al., 1983; REUNANEN et al., 1996; LEE et al., 2005; SOINIO et al., 2007; PRASAD, 2008; CATANIA et al., 2009).
Outro mineral que se pode citar é o cálcio, que é responsável por muitas funções fisiológicas importantes, como proliferação celular, respostas a hormônios e liberação de neurotransmissores (BASS \& CHAN, 2006). O ferro por sua vez é responsável pelo transporte de oxigênio na hemoglobina, além de ser um substrato vital para a produção de hemoglobina (TAY et al., 2011). Por fim pode-se citar o cobre que desempenha um papel vital como cofator para uma variedade de enzimas (MEGIAS et al., 2007).

Além desses fatos, a amêndoa de cupuaçu deste trabalho, apresentou um teor de macro e micronutrientes superiores ao do cacau exceto pela quantidade de $\mathrm{N}(25,9 \mathrm{~g} / \mathrm{kg}), \mathrm{P}(3,6 \mathrm{~g} / \mathrm{kg})$ e Fe $(70$ $\mathrm{mg} / \mathrm{kg}$ ) de acordo com os resultados de Belchior \& Inés (2013).

\section{CONCLUSÃO}

As transformações bioquímicas nas sementes de cupuaçu foram percebidas ao longo da fermentação, pois o comportamento do $\mathrm{pH}$, temperatura, acidez e ${ }^{\circ}$ Brix foram os responsáveis por influenciar nas condições para o desenvolvimento de microrganismos 
durante a fase anaeróbica e aeróbica da fermentação, resultando nas transformações bioquímicas na semente.

As alterações que a semente sofreu até se tornar amêndoa foi acompanhada por uma perda de bioativos, dentre eles se destaca uma redução significativa de compostos fenólicos totais (redução de 66\%), responsáveis pela adstringência e amargo no produto, além de flavonoides totais (redução de 40\%) e vitamina C (redução 79\%), o que culminou na redução da capacidade antioxidante da amostra, apresentando uma redução de 32,73\% em AB'Ts, enquanto que em DPPH a redução foi maior, cerca de $72 \%$.

Destaca-se a ação enzimática observada no trabalho da PPO e POD, responsáveis por oxidar compostos fenólicos que apresentaram alta afinidade com estas enzimas, principalmente, durante a fermentação resultando em quinonas que se polimerizam e viram melanoidinas, gerando a coloração marrom nos cotilédones da semente de cupuaçu.

As amêndoas foram classificadas como tipo II segundo a normativa vigente e apresentaram um grande potencial nutricional, em virtude de apresentar uma boa quantidade de macro e micronutrientes que superaram o cacau exceto pelo teor de ferro, potássio e nitrogênio.

Com base neste trabalho foi possível avaliar os processos bioquímicos do beneficiamento das sementes de cupuaçu, pode-se constatar que para desenvolver o aroma e as características peculiares, a semente precisou passar por processos fermentativos, secagem e torração que podem ser responsáveis pelas transformações bioquímicas necessárias para os atributos peculiares do cupulate. Por fim, as amêndoas apresentam concentração de alcaloides, macro e micro nutrientes, compostos bioativos, o que indica que é uma fonte nutritiva com capacidade antioxidantes e apresenta um beneficiamento semelhante ao cacau, porém com características próprias.

\section{REFERÊNCIAS}

Afoakwa EO, Kongor JE, Budu AS, Mensah-Brown H., Takrama JF. Changes in some biochemical qualities during drying of pulp preconditioned and fermented cocoa (Theobroma cacao) beans. Afr. J. of Food, Agri., Nutrition and Devel. 2015; 15(1): 9651-9670.

Afoakwa EO, Kongor JE, Takrama J, Budu AS. Changes in nib acidification and biochemical composition during fermentation of pulp preconditioned cocoa (Theobroma cacao) beans. Food Res Int. J. 2013; 20(4): 1843-1853.

Ahn MR, Kumazawa S, Usui Y, Nakamura J, Matsuka M, ZHU F, Nakayama T. Antioxidant activity and constituents of propolis collected various areas of China. Food Chem. 2007; 101: 13831392.

Association Of Official Analytical Chemists. Official Methods of analysis of AOAC International. Maryland: AOAC International; 2005

Bass JK, Chan GM. Calcium nutrition and metabolism during infancy. Nutrition. 2006; 22(10): 1057 1066.

Belchior TO, Inés MG. Chemical composition of cupuaçu (Theobroma grandiflorum) and cocoa (Theobroma cocoa) liquors and their effects on streptozoctocin-induced diabetic rats. Food Res Int. 2013; 51 (2): 929-935.

Biehl B, Passern D. proteolysis during fermentation-like incubation of cacao seeds. J. Sci. Fd. Agric. 1982; 33: $1280-1290$.

Biehl B, Ziegleder G. COCOA Chemistry of processing. Encyclopaedia of Food Sciences and Nutrition. 2003; 2 (3): 1436 - 1448.

Bradford MM. A rapid and sensitive method for the quantification of microgram quantities of protein-dye binding. Anal Biochem. 1976; 72 (12): $248-254$.

Braga SCGN, Oliveira LF, Hashimoto JC, Gama MR, Efraim P, Joppi RJ, Augusto F. Study of volatile profile in cocoa nibs, cocoa liqour and chocolate on production process using GC X GX-QMS. Microchem J. 2018; 141: 353-361.

Brasil. Instrução Normativa $n^{\circ} 57$ de 12 de nov. de 2008, Regulamento Técnico da Amêndoa de 
Cacau. Diário Oficial da União, Brasília; 2008 [acesso em 02 de jan 2020]. Disponível em: http://sistemasweb.agricultura.gov.br/sislegis/a ction/detalhaAto.do? method=visualizarAtoPor talMapa\&chave $=1977518492$.

Brito ES. A Fermentação do Cacau: uma revisão. Universidade Federal de Campinas; 1996.

Canuto G, Xavier A, Neves L, Benassi M. Caracterização físico-química de polpas de frutos da Amazônia e sua correlação com a atividade anti-radical livre. Rev. Bras. Frutic. 2010; 32(4): 1196-1205.

Carvalho A, García N, Wada J. Caracterização físicoquímica e curvas de solubilidade proteica de sementes, amêndoas fermentadas e torradas de cupuaçu (Theobroma grandiflorum Schum). Braz. J. Food Technol. 2005; 8 (2): 127-134.

Castro Z. Caracterización del proceso de fermentación del grano de copoazú (Theobroma grandiflorum Willd. ex spreng) [dissertação]. Bogotá: Universidad Nacional de Colombia; 2010.

Catania AS, Barros CR, Ferreira SRG. Vitaminas e minerais com propriedades antioxidantes e risco cardiometabólico: controvérsias e perspectivas. Arq Bras Endocrinol Metabol. 2009; 53 (5): 550559.

Chitarra AB, Prado MET. Utilização de atmosfera modificada e controlada em frutos e hortaliças. Lavras: UFLA/FAEPE; 2002.

Cohen O, Jackix H. Estudo do liquor de cupuaçu. Ciênc. Tecnol. De Alimentos. 2005; 25(1):18290 .

Costa CS. Influência dos processos de fermentação e secagem no teor de compostos fenólicos e capacidade antioxidante de amêndoas de cacau amazônico (Theobroma cacao var. Forasteiro) [dissertação]. Belém: Universidade Federal Do Pará; 2013.

Costa MP, Monteiro MLG, Frasao BS, Silva VLM, Rodrigues BL, Chiappini CCJ, Conte-Junior CA. "Consumer perception, health information, and instrumental parameters of cupuassu (Theobroma grandiflorum) goat milk yogurts", J Dairy Sci. 2017; 100: 1-12.
Costa RS, Teixeira CB, Gabbay Alves TV, RibeiroCosta RM, Casazza AA, Aliakbarian B, Perego P. Optimization of spray drying conditions to microencapsulate cupuassu (Theobroma grandiflorum) seed by-product extract. Nat. Prod. Res. 2019; 33 (18): 2600-2608.

Efraim P, Alves AB, Jardim DCP. Review: Polyphenols in cocoa and derivatives: factors of variation and health effects. Braz. J. Food Technol. 2011; 14 (3): 181-201.

Efraim P, Pezoa-García NH, Jardim DCP, Nishikawa A, Haddad R, Eberlin MN. Influência da fermentação e secagem de amêndoas de cacau no teor de compostos fenólicos e na aceitação sensorial. Ciênc. Tecnol. De Alimentos. 2010; 30: 142-150.

Efraim P. Contribuição a melhoria de qualidade de produtos de cacau no Brasil, por meio da caracterização de derivados de cultivares resistentes a vassoura-de-bruxa e de sementes danificadas pelo fungo [tese]. Campinas: Universidade Estadual de Campinas; 2009.

Efraim P. Estudo para minimizar as perdas de flavonoides durante a fermentação de cacau para produção de chocolate [tese] Campinas: Universidade Estadual de Campinas; 2004

Elba PS, Ferrara MA, Corvo ML. Enzimas em biotecnologia: produção, aplicações e mercado. Interciência; 2008.

Embrapa. Manual de Análises Químicas de Solos, Plantas e Fertilizantes. 2 ed. Embrapa Informação Tecnológica, Brasília, DF; 2009.

Fernandes SC, Oliveira IRWZ, Vieira IC. A green bean homogenate immobilized on chemically crosslinked chitin for determination of caffeic acid in white wine. Enzyme Microb. Technol. 2007; 40 (1): 661-668.

Ferrão JEM. A 'morte da semente' sua importância na tecnologia pós-colheita do cacau. Revista de Ciências Agrárias. 2007; 31(1): 262 - 267.

Garcia, I. P. Enzimas produzidas durante os diferentes estágios de fermentação das sementes de cupuaçu (Theobroma grandiflorum (willdenow ex sprengel) schumann) [dissertação]. Manaus: Universidade Federal do Amazonas; 2006. 
Gruber AP. Compostos fenólicos do cupuaçu (Theobroma grandiflorum) e do cupulate: Composição e possíveis benefícios [Mestrado]. São Paulo: Universidade De São Paulo; 2010.

Guehi TG, Zahouli IB, Ban-Koffi L, Fae MA, Nemlin JG. Performance of different drying methods and their effects on the chemical quality attributes of raw cocoa material. Int J Food Sci Technol. 2010; 45(8): 1564-1571.

Hansen CE, Del Olmo M, Burri C. Enzyme activities in cocoa beans during fermentation. J Sci Food Agric. 1998; 77(2): 273-281.

Instituto Adolf Lutz. Métodos físico-químicos para análise de alimentos/ coordenadores Odair Zenebon, Neus Sadocco Pascuet e Paula Tigela - São Paulo: Instituto Adolf Lutz; 2008.

Janek K, Niewienda A, Wöstemeyer J, Voigt J. The cleavage specificity of the aspartic protease of cocoa beans involved in the generation of the cocoa-specific aroma precursors. Food Chem. 2016; 211: 320-328.

Jinap S, Lioe H, Yusep I, Nazamid S. Role of carboxypeptidases to the free amino acids composition, methylpyrazine formation and sensory characteristics of under-fermented cocoa beans. Food Res Int. 2010; 17: 763-774.

Kinlaw WB, Levine AS, Morley JE, Silvis SE, Clain CJ. Abnormal zinc metabolism in type II diabetes mellitus. Am J Med. 1983;75 (2): 273-277.

Kuskoski EM, Asuero AG, García-Parilla MC, Troncoso AM, Fett R. Actividad antioxidante de pigmentos antocianicos. Food Sci. Technol. 2004; 24 (4): 691-693.

Lee DH, Folsom A, Jacobs D. Iron, zinc, and alcohol consumption and mortality from cardiovascular diseases: the Iowa Women's Health Study. Am J Clin Nutr. 2005; 81 (4):787-791.

Linewever H., Burk D. The determination of enzyme dissociation constants. J. Am. Chem. 1934; 56 (1): 658-666.

Lo Coco F, Lanuzza F, Micali G, Cappellano G. Determination of theobromine, theophylline, and caffeine in by-products of cupuacu and cacao seeds by high-performance liquid chromatography. J. Chromatogr. Sci. 2007; 45(5): 273-275.

Lopes A, Pezoa-García N, Amaya-Farfán J. Qualidade nutricional das proteínas de cupuaçu e de cacau. Ciênc. Tecnol. Aliment. 2008; 28 (2): 263-268.

Lopes AS. Estudo químico e nutricional de amêndoas de cacau (Theobroma cacao L.) e cupuaçu (Theobroma grandiflorum Schum) em função do processamento [dissertação]. Campinas: Universidade Estadual de Campinas; 2000.

Lopez AS, Dimick PS. Enzymes Involved in Cocoa Curing. In: Food Enzymology, ed. Fox, P.F. Elsevier Science Publisher ltd. London; 1991.

Maldonade IR, Rodriguez-Amaya D, Scamparini ARP. Carotenoids yeasts isolated from the Brazilian ecosystem. Food Chem. 2008; 107 (1): 145-150.

Marshall RM, Kim J, Wei CI. Enzymatic browning in fruits, vegetables and Seafoods. FAO. 2000; 49: $1-49$.

Mattietto R. Estudo comporativo das transformações estruturais e físico-químicas durante o processo fermentativo de amêndoas de cacau (Theobroma cacao) e cupuaçu (Theobroma grandiflorum) [dissertação]. São Paulo :Universidade Estadual de Campinas; 2001

Meda A, Lamien CE, Romito, M, Millogo J, Nacoulma OG. Determination of the total phenolic, flavonoid and proline contents in Burkina Fasan honey, as well as their radical scavenging activity. Food Chem. 2005; 91: 571-577.

Meersman E, Steensels J, Mathawan M, Wittocx PJ, Saels V, Struyf N, Verstrepen KJ. Detailed analysis of the microbial population in Malaysian spontaneous cocoa pulp fermentations reveals a core and variable microbiota. Plot One. 2013; 8 (12): $1-10$.

Megias C, Pedroche J, Yust MM, Giron-Calle J, Alaiz M, Millan F. Affinity purification of copper chelating peptides from chickpea protein hydrolysates. J. Agric. Food Chem. 2007; 55(10): 3949 - 3954

Mensor LL, Menezes FS, Leitão GG, Reis AS, Santos TCD, Coube CS, Leitão SG. Screening of Brazilian plant extracts for antioxidant activity by 
the use of DPPH free radical method. Phytother Res. 2001; 15 (2): 127-130.

Misnawi C, Jinap S, Jamilah B, Nazamid S. Sensory properties of cocoa liquor as affected by polyphenol concentration and duration of roasting. Food Qual Prefer. 2004; 15: 403-409.

Nazaré RFR, Barbosa WC, Viêgas RMF. Processamento das sementes de cupuaçu para a obtenção de cupulate. Belém, PA: Embrapa CPATU; 1990.

Ortega N, Romero MP, Macià A, Reguant J, Anglès N, Morelló JR, Motilva MJ. Obtention and characterization of phenolic extracts from different cocoa sources. J Agr Food Chem. 2008; 56: 9621-9627.

Ortolan F. Caracterização e fatores relacionados à alteração de cor da farinha [tese]. Santa Maria: Universidade Federal de Santa Maria; 2006.

Paramo D, Garcia-Alamilla P, Salgado-Cervantes MA, Robles-Olvera VJ, Rodriguez-Jimenes GC. Mass transfer of water and volatile fatty acids in cocoa beans during drying. J. Food Eng. 2010; 99(3): $276-283$.

Paula GA. Caracterização físico-química e estudo do escurecimento enzimático em produtos derivados de açaí (Euterpe oleracea Mart.) [dissertação]. Fortaleza: Universidade Federal do Ceará; 2007.

Pereira ALF, Abreu VKG, Rodrigues S. Cupuassu Theobroma grandiflorum. Elsevier Inc Exotic fruits; 2018.

Pereira ALF, Feitosa WSC, Abreu VKG, Lemos TO, Gomes WF, Narain N, Rodrigues S. "Impact of fermentation conditions on the quality and sensory properties of a probiotic cupuassu (Theobroma grandiflorum) beverage", Food Res Int. 2017; 100: 603-611.

Prasad AS. Clinical, immunological, anti-inflammatory and antioxidant roles of zinc. Exp Gerontol. 2008; 43(5): 370 - 377.

Pugliese A, Tomas-Barberan F, Truchado P, Genovese M. Flavonoids, Proanthocyanidins, Vitamin C, and Antioxidant Activity of Theobroma grandiflorum (Cupuassu) Pulp and Seeds. J. Agric. Food Chem. 2013; 61: 2720- 2728.
Pugliese AG. Compostos fenólicos do cupuaçu (Theobroma grandiflorum) e do cupulate: Composição e possíveis benefícios [dissertação]. São Paulo: Universidade de São Paulo; 2010.

Reunanen A, Knekt P, Marniemi J, Mäki J, Maatela J, Aromaa A. Serum calcium, magnesium, copper and zinc and risk of cardiovascular death. Eur J Clin Nutr. 1996; 50 (7): 431-437.

Rizzi G, Bunke P. The use of roasting kinetics data to characterize natural and artificial chocolate aroma precursors. Developments Food Sci. 1998; 40: 535-546.

Rusconi M, Conti A. Review Theobroma cacao L., the Food of the Gods: A scientific approach beyond myths and claims. Pharmacol. Res. 2010; 61 (1): 5-13.

Salvador I. Atividade antioxodante e teor de revesratrol em cacau, chocolates achocolatados em pó e bebidas lácteas achocolatadas [dissertação]. São Paulo: Universidade do Estado de São Paulo; 2011.

Sapers GM, Hicks KB, Phillips JG, Garzarella LG, Pondish DL, Matulaitis RM, Mccormac TJ, Sondey SM, Seib PA, Elatawy YS. Control of enzymatic browning in apple with ascorbic acid derivatives, polyphenol oxidase inhibitors and complexing agents. J. Food Sci. 1989; 54: 9971002.

Schwan R, Wheals A. The microbiology of cocoa fermentation and its role in chocolate quality. Crit. Rev. Food Sci. Nutr. 2004; 44(4): 205-221.

Shufen LIJ, Berger S, Hartlan D. UV spectrophotometric determination of theobromine and caffeine in cocoa beans. Anal. Chim. Acta. 1990; 232: 409-412.

Singleton VL, Orthofer R, Lamuela RM. Analysis of total phenols and other oxidation substrates and antioxidants by means of Folin-Ciocalteu reagent. Method Enzymol. 1999; 1: 152-178.

Soares MS. Estudo de melhoramento do sabor de cacau (Theobroma cacao L.) através de ação enzimática durante a fermentação [dissertação]. Campinas: Universidade Estadual de Campinas; 2001.

Soinio M, Marniemi J, Laakso M, Pyorala K, Lehto S, Ronnemaa T. Serum zinc level and coronary 
heart disease events in patients with type 2 diabetes. Diabetes Care. 2007;30(3): 523-528.

Song W, Derito CM, Liu MK, He X, Dong M, Liu RH. Cellular antioxidant activity of common vegetables. J Agr Food Chem. 2010; 58 (11): 6621-6629.

Souza AGC. Boas práticas agrícolas da cultura do cupuaçuzeiro. Embrapa Amazônia Ocidental, Manaus; 2007.

Tay ELW, Peset A, Papaphylactou M, Inuzuka R, Alonso-Gonzalez R, Giannakoulas G. Replacement therapy for iron deficiency improves exercise capacity and quality of life in patients with cyanotic congenital heart disease and/or the Eisenmenger syndrome. Int. J. Cardiol. 2011; 151(3): 307 - 312.

Toker OS, Palabiyik I, Pirouzian HR, Aktar T, Konar N. Chocolate aroma: Factors, importance and analysis. Trends Food Sci Tech. 2020; 99: 580592.

Toro MJU, Santos FAF, Costa IF. Variação dos compostos polifenois durante a fermentação e secagem das amêndoas de cupuaçu (theobroma grandiflorum) e cupuí (theobroma subincanum). In: XIX ENAAL. Rio Grande do Norte; 2015. 155 $-161 \mathrm{p}$.

Vieira IC, Lupetti KO, Fatibello-Filho O. Determinação de paracetamol em produtos farmacêuticos usando um biossensor de pasta de carbono modificado com extrato bruto de abobrinha (Cucurbita pepo). Quim. Nova. 2003; 26 (1): 39-43.

Wollgast J, Anklam E. Review on polyphenols in Theobroma cacao: changes in composition during the manufacture of chocolate and methodology for identification and quantification. Food Res Int. 2000; 33: 423-447.

Yang H, Protiva P, Cui B, Ma C, Baggett S, Hequet V, Mori S, Weinstein IBE, Kennelly EJ. New Bioactive Polyphenols from Theobroma grandiflorum ("Cupuaçu”). J. Nat. Prod. 2003; 66: 1501-1504.

Yoruk R, Marshall MR. Physicochemical proprieties and function of plant polyphenol oxidase: A review. J. Food Biochem. 2003; 27: 361-422.

Zamalloa WAC. Cartacterização físico-química e avaliação de metilpirazinas no de senvolvimento do sabor, em dez cultivares de cacau (Theobroma cacau L.) produzido no Estado de Sao Paulo [dissertação]. Campinas: Universidade Estadual de Campinas; 1994.

Zambrano A, Romero C, Gómez A, Ramos G, Lacruz C, Brunetto MR, Gallignani M, Gutiérrez L, Delgado Y. Evaluación química de precursores de aroma y sabor del cacao criollo merideño durante la fermentación en dos condiciones edafoclimáticas. Agron Trop. 2010; 60(2): 211219 